\title{
Medicinal plants possessed beneficial therapeutic effects in Alzheimer's disease and memory deficits
}

\author{
Ali Esmail Al-Snafi * \\ Dept. of Pharmacology, College of Medicine, University of Thi qar, Iraq.
}

GSC Biological and Pharmaceutical Sciences, 2021, 17(02), 008-033

Publication history: Received on 24 September 2021; revised on 27 October 2021; accepted on 29 October 2021

Article DOI: https://doi.org/10.30574/gscbps.2021.17.2.0321

\begin{abstract}
Alzheimer's disease is the most common cause of dementia, accounting for an estimated $60 \%$ to $80 \%$ of cases. The treatment of Alzheimer's disease remains challenging. Many medicinal plants possessed beneficial therapeutic effect inAlzheimer's disease and memory deficits, by their anti-inflammatory, antioxidant, neuroprotective, NF- $\kappa B$ inhibition, phosphodiesterase inhibition, anti-amyloidogenic, and anticholinesterase activities. In the current article, the medicinal plants with beneficial effects in Alzheimer's disease and memory deficits were discussed. This article considers not only the therapeutic effect of medicinal plants in AD and memory deficits, but also discussed the mechanisms of their beneficial effects.
\end{abstract}

Keywords: Medicinal plants; Alzheimer's disease; Memory deficits; Mechanisms

\section{Introduction}

Alzheimer's disease (AD) is a progressive neurological disease of the brain, it is the most common form of dementia and affects an estimated 10 million people worldwide. Memory impairment is the hallmark symptom of Alzheimer's disease. Dementia is characterized by progressive deterioration in cognitive domains, including memory, language, executive and visuospatial function, personality and behavior. Many studies revealed that people with Alzheimer seem like they have lost their memory, challenges in planning or solving problems, gradually loss of capability to achieve normal task, puzzling day from night, loss of visualization and coordination, inappropriate use of words, inability to recognize and use familiar objects, mood change. Etiology of Alzheimer involved environmental factors, genetic factors, neuroinflammation, synaptic dysfunction, head injuries, oxidative stress, social stressors, mitochondrial impairment, bloodbrain barrier disruption, nutritional deficiencies, down's syndrome, cardiovascular disease (hyperlipidemia, high blood), lifestyle factors (poor-quality sleep, lack of exercise, and poor nutrition), as well as metabolic conditions such as diabetes and obesity also plays role in building Alzheimer, while pathophysiology represents dysfunctional neurotransmission of acetylcholine, stress-associated signaling cascades (GABA ergic, glutamate ergic) and abnormal extracellular accumulation of $ß$-amyloid plaque deposition and neurofibrillary tangles of hyperphosphorylated microtubule-associated protein Tau [1-3].

Many medicinal plants possessed beneficial therapeutic effect in Alzheimer's disease and memory deficits [4-6], by their anti-inflammatory, antioxidant, neuroprotective, NF- $\mathrm{BB}$ inhibition, phosphodiesterase inhibition, anti-amyloidogenic, and anticholinesterase activities [7-11]. In this article, the beneficial effects of medicinal plants in the treatment of memory deficitsand Alzheimer's disease were discussed. This article considers not only the therapeutic effect of medicinal plants in $\mathrm{AD}$, but also in the understanding the mechanisms of their beneficial effects.

\footnotetext{
${ }^{*}$ Corresponding author: Ali Esmail Al-Snafi

Dept. of Pharmacology, College of Medicine, University of Thi qar, Iraq.
} 


\section{Medicinal plants with beneficial therapeutic effects in Alzheimer's disease and memory deficits}

\subsection{Anchusa italic}

Abnormal Savda Munsiq (ASMq) contained Anchusa italica, when administered orally, it produced memory-enhancing effect in the chronic stressed mice induced by electric foot-shock. The memory improvement of the stressed mice was shown by anincrease of the latency time in the step-through test and the decrease of the latency time in the Y-maze test. ASMq induced marked decrease in the serum levels of corticosterone, ACTH and $\beta$-endorphin as well as the brain and serum level of norepinephrine. Furthermore, ASMq was able to significantly reverse the chronic stress by decreasing the brain and serum levels of the monoamine neurotransmitters dopamine, 5-hydroxytryptamine and 3, 4dihydroxyphenylalanine [12-13].

\subsection{Antirrhinum majus}

Aurones and extracts comprising them were useful in the prophylactic and/or therapeutic treatment of an animal and human with a phosphodiesterase dependent disease of the central nervous system included Alzheimer's disease, age related dementia, learning and memory disorders, and ischemia of the central and/or peripheral nervous systems [1415].

\subsection{Bacopa monniera}

The effect of 14 days administration of the extract of Bacopa monniera (BM, bacoside A content $82.0 \pm 0.5 \%$ ) on two animal models of Alzheimer's disease, induced by colchicine and by lesion induced in the nucleus basalis magnocellularis with ibotenic acid. Colchicine and ibotenic acid induced significant deficits in the retention of avoidance learning, which was evident on day 7, after lesioning, and increased progressively by day 14. Subchronic administration of BM reduced the magnitude of memory deficits induced by both colchicine and ibotenic acid, which was significant at days 7 and 14 with the higher dose, $10 \mathrm{mg} / \mathrm{kg}$, orally, and on day 14 only with the lower dose, $5 \mathrm{mg} / \mathrm{kg}$ orally, of BM. $\mathrm{BM}(10 \mathrm{mg} / \mathrm{kg}$, orally) reversed colchicine-induced reduction in frontal cortex and hippocampal Ach, ChAT activity and MCR binding. The effect of the lower dose of BM $(5 \mathrm{mg} / \mathrm{kg}$, orally) was evident only after 14 days [16].

Memory deficits following cholinergic blockade by scopolamine were reversed by Bacopa treatment [17]. It also reversed the diazepam induced amnesia [18].

Bacopa administration with phenytoin significantly reversed phenytoin-induced cognitive impairment, as noted by improved acquisition and retention of memory [19].

A clinical trial was performed to investigate the effects of administration of Bacopa monnieri (300mg/day, for 12 weeks) on memory performance in people over the age of 55-years.Bacopa significantly improved memory acquisition and retention in older persons [20].

A double-blind, 12-week trial utilizing the same dose of Bacopa extract (300 mg daily) containing 55\% combined bacosides, was carried out. Forty-six healthy volunteers were randomly divided into treatment and placebo groups. The same dosage trial were administered at baseline, five, and 12 weeks after treatment began. After 12-week, a significant improvement in verbal learning, speed of early information processing and memory consolidation were recorded in the treated group compared to placebo. These effects were not observed at baseline or at five weeks [21].

In a double-blind randomized, placebo control study carried out on 76 adults (40 and 65 years), in which various memory functions were tested and levels of anxiety was measured, the rate of learning was unaffected by Bacopa monnieri suggesting that Bacopa monnieri decreases the rate of forgetting of newly acquired information. Verbal and visual short-term memory, attention, and the retrieval of pre-experimental knowledge were unaffected. Questionnaire measures of everyday memory function and anxiety levels were also unaffected [22-23].

\subsection{Bellis perennis}

The effects of aqueous extract of Bellis perennis flowers were tested in anxiety-like behavior and memory in rats. At a dose of 20 and $60 \mathrm{mg} / \mathrm{kg}$, rats spent more time at the center, showed less mobility and velocity. With the using of high Bellis perennis dose, rats spent more time, spent less time in the closed arms, less mobile, and slower and rotated less frequently. In the Morris water maze, the high dose of Bellis perennis administrated rats spent more of the time to find the platform. In conclusion, Bellis perennis may produce biphasic effects on learning performance of the rats [24-25]. 


\subsection{Benincasa hispida}

The treatment with an aqueous extract of pulp of Benincasa hispida $(400 \mathrm{mg} / \mathrm{kg} \mathrm{bw})$ revealed beneficial effect in the management of colchicines-induced rat model of Alzheimer's disease. It was also increased antioxidants in different brain areas and increased the number of correct choices out of 10 daily trials and decreased latency time dose dependently [26-28].

\subsection{Brassica nigra}

The effect of B. nigra fixed oil on the changes in memory caused by $\beta$-amyloid was studied in rats. The gavage of oil ( 925 $\mathrm{mg} / \mathrm{kg}$ ) to rats receiving $\beta$-amyloid, significantly decreased the traveled distance and the required time for finding hidden platform on the training days and increased the time of presence in the target quadrant on the test days [29-31].

\subsection{Caesalpinia crista}

The ability of Caesalpinia crista leaf aqueous extract was studied on the prevention of (a) the formation of oligomers and aggregates from monomers, the formation of fibrils from oligomers and dis-aggregation of pre-formed fibrils: aqueous extract added to matured fibrils and incubated for 9 days). The aggregation kinetics was monitored using thioflavin-T assay and transmission electron microscopy. The aqueous extract of Caesalpinia crista inhibited the Amyloid beta (42) aggregation from monomers and oligomers and also able to dis-aggregate the pre-formed fibrils [32].

The aqueous extract of Ceasalpinia crista dried seed kernels was tested as learning and memory enhancer. The memory retention in mice treated with $50 \mathrm{mg} / \mathrm{kg}$ aqueous extract of dried seed kernels of Caesalpinia crista against scopolamine induced amnesia was found to be $33.09 \%$ in radial arm maze task performance. However, the memory retention increased to $45.29 \%$ in mice treated with $150 \mathrm{mg} / \mathrm{kg}$ (iv) of the same extract. Accordingly, the authors suggested that the extract could be beneficial to improve cognition in disorders like dementia and various neurodegenerative disorders [33-34].

\subsection{Carthamus tinctorius}

The neuroprotective activity of herbal combination contained Carthamus tinctorius were investigated in mitigating brain infarction and global ischemia as well as preventing the neurodegeneration following ischemia. They improved cerebral blood circulation, which refer to a potential to alleviate the symptoms of degenerative diseases, Alzheimer's disease and Parkinson's disease [35].

The neuroprotective effects of hydroxysafflor yellow A (HSYA) on cerebral ischemic injury in both in vivo and in vitro were studies. Male rats with middle cerebral artery occlusion (MCAO) were evaluated for neurological deficit scores followed by the treatment with a single dose of HSYA. The infarction area of the brain was estimated in the brain slices. the effect of HSYA was also investigated in vitro on fetal cortical cells exposed to glutamate and sodium cyanide (NaCN) to identify its neuroprotection against neurons damage. The results of in vivo study showed that sublingular vein injection of HSYA at doses of $3.0 \mathrm{mg} / \mathrm{kg}$ and $6.0 \mathrm{mg} / \mathrm{kg}$ exerted significant neuroprotective effects on rats with focal cerebral ischemic injury by marked decreasing neurological deficit and reducing the infarct area compared with the saline group, HSYA at a dose of $6.0 \mathrm{mg} / \mathrm{kg}$, gave a similar potency as nimodipine at a dose of $0.2 \mathrm{mg} / \mathrm{kg}$. Sublingular vein injection of HSYA at the dose of $1.5 \mathrm{mg} / \mathrm{kg}$ showed a neuroprotective effect, however, with no significant difference when compared with the saline group. In vitro results showed that HSYA significantly inhibited neuron damage induced by exposure to glutamate and sodium cyanide $(\mathrm{NaCN})$ in cultured fetal cortical cells, however, the neuroprotective action of HSYA on glutamate-mediated neuron injury was much better than that of HSYA on NaCN-induced neuron damage [36-37].

\subsection{Cistanche tubulosa}

The ameliorating effects of Cistanche tubulosa extract which was quantified with three phenylpropanoid glycosides was studiedin Amyloid $\beta$ peptide 1-42 (A 1-42) intracisternally induced Alzheimer's disease (AD) in rat. A 1 1-42 caused cognitive deficits, increased acetylcholine esterase activities and amyloid deposition and decreased brain acetylcholine and dopamine. Daily administration of Cistanche tubulosa extract decreased amyloid deposition, ameliorated the cognitive deficits and reversed cholinergic and dopaminergic dysfunction caused by A $\beta$ 1-42 [38].

The effect and safety of Cistanche tubulosa glycoside capsules (Memoregain ${ }^{\circledR}$ capsule) in the treatment ofAlzheimer's disease were studied clinically. A total of 18 patients with AD administered with 
Memoregain ${ }^{\circledR}$ was given for 48 weeks and investigated for efficacy by Alzheimer's disease assessment scale-cognitive subscale, mini-mental state examination, activities of daily living, blessed behavioral scale, and clinical global impression scales. The mini-mental state examination score was $14.78 \pm 2.51$ at baseline and $14.06 \pm 4.26$ at study completion. While changes in disease assessment scale-cognitive subscale score before and after 48 weeks of treatment were statistically insignificant, the score improved, deteriorated, and remained unchanged in 10, 7, and 1 patients, respectively. The ADL and CGI scores showed no significant difference from baseline. All adverse reactions were mild. After Memoregain ${ }^{\circledR}$ treatment, patients with AD showed no obvious aggravation of cognitive function, independent living ability, and overall conditions but were stable throughout the study. Comparison with other long-term medications, acetylcholinesterase inhibitors suggests that Memoregain ${ }^{\circledR}$ has a potential to be a possible treatment option for mild to moderate AD [39-40].

The body of Cistanche tubulosa (Schenk.) Wight, was used to make a medicinal preparation containing phenylethanoid glycosides and comprising 10-70\% of echinacoside and 1-40\% of acteoside by weight of the preparation. The medicinal preparation was used effectively in prevention of senile dementia, and inhibition of aggregation of blood platelets [41].

The improvement of learning ability and consolidation of Cistanche tubulosa extract was carried out with a step-down test in mice. In this method, a platform (safe area) is located on an electric wire with $36 \mathrm{~V}$ current and mice's learning ability and consolidation were evaluated by the time they spend on the platform and the number of electronic shocks they received. Scopolamine (which may retard learning ability) was administered before the training started, and sodium nitrite (a drug to inhibit the synthesis of protein involved in the formation of memory by inducing oxygen deficit in the brain) was administered after the training in order to induce learning/memory disorder. As a result, the safe area time (latency) and the number of errors (frequency that mice hit by electronic shocks) were significantly better in the Cistanche tubulosa extract administration group as compared to the memory consolidation dysfunction model group. Cistanche tubulosa extract exerted stronger activity than piracetam, a pharmaceutical agent to activate energy metabolism of brain cells. According to these results, Cistanche tubulosa extract significantly helped the brain to recover from scopolamine-induced learning disorder and sodium nitrite-induced memory consolidation dysfunction and it improved the learning ability and formation of memory of brain [42].

On the other hand, water maze test was carried out to evaluate the memory recall ability of mice. Training was conducted to create memory in mice on the routes of water maze. Cistanche tubulosa extract (50-400 mg/kg) were orally administered to mice every day throughout the training period, four weeks. On the last day of the training, $30 \%$ ethanol was given to mice to induce memory loss (failing to recall memorized information). The mice in group consuming Cistanche tubulosa extract required shorter time to arrive destination compared to control. The rate of error was significantly lower in group consuming Cistanche tubulosa extract. Cistanche tubulosa demonstrated stronger activity than piraceetam. Accordingly, Cistanche tubulosa extract improved the ability to elicit or recall memorized information [43-44].

\subsection{Citrus limon}

The effect of Citrus limon on memory of mice was studied using Harvard Panlab Passive Avoidance response apparatus controlled through LE2708 Programmer. Passive avoidance was fear-motivated tests used to assess short or long-term memory of small animals, which measures latency to enter into the black compartment. Animals with Citrus limon treatment showed significant increase in latency to enter into the black compartment after 3 and 24 hours than control [45-46].

\subsection{Clitoria ternatea}

Seeds and leaves of Clitoria ternatea have been widely used as brain tonic and believed to promote memory and intelligence. The activity of Clitoria ternatea in Alzheimer's disease was studied to investigate its efficacy and to identifythe major bioactive constituent attributing the activity.The result showed that the aqueous extract of Clitoria ternatea was beneficial in Alzheimer's disease through many mechanisms. The isolated compounds may act as a lead compounds for identifying new derivatives which could use for improving memory [47-48].

Shankhpushpi, a well-known drug in Ayurveda, is extensively used for different central nervous system (CNS) effects especially memory enhancement. Different plants were used under the name shankhpushpi in different regions of India, leading to an uncertainty regarding its true source. Plants commonly used under the name shankhpushpi are: Convolvulus pluricaulis., Evolvulus alsinoides, both from Convolvulaceae, and Clitoria ternatea from Leguminosae. The memory-enhancing activity of thesethree plants wasinvestigated. Anxiolytic, antidepressant and CNS-depressant activities of these three plants were also evaluated and compared. The nootropic activity of the aqueous methanol extract of each plant was tested using elevated plus-maze (EPM) and step-down models. Anxiolytic, antidepressant and 
CNS-depressant studies were evaluated using EPM, Porsolts swim despair and actophotometer models. Clitoria ternatea extract (CTE) showed maximum memory-enhancing and anxiolytic activity $(\mathrm{p}<0.001)$ at 200 and $100 \mathrm{mg} / \mathrm{kg}$, respectively. Amongst the three plants, Clitoria ternatea extract (CTE) showed significant $(\mathrm{p}<0.05)$ antidepressant activity. All the three plants showed CNS-depressant action at higher dose levels [49].

Treatment with $100 \mathrm{mg} / \mathrm{kg}$ of Clitoria ternatea aqueous root extract (CTR) for 30 days in neonatal and young adult rats, significantly increased acetylcholine (ACh) content in their hippocampi as compared to age matched controls. Increase in ACh contents in their hippocampus may represent the neurochemical basis for their improved learning and memory [50].

For the studying of the mechanisms of memory enhancement of the Clitoria ternatea aqueous root extract, young adult ( 60 day old) Wistar rats of either sex were orally intubated with 50 and $100 \mathrm{mg} / \mathrm{kg}$ bw of aqueous root extract of Clitoria ternatea (CTR) for 30 days, along with age-matched saline controls. These rats were then subjected to passive avoidance tests and the results showed a significant increase in passive avoidance learning and retention. The amygdale of these rats were processed for Golgi staining and the stained neurons were analysed. The results showed a significant increase in dendritic intersections, branching points and dendritic processes arising from the soma of amygdaloid neurons in CTR treated rats especially in the $100 \mathrm{mg} / \mathrm{kg}$ group of rats compared with age-matched saline controls [51].

The effectiveness of alcoholic extracts of aerial and root parts of Clitoria ternatea at 300 and $500 \mathrm{mg} / \mathrm{kg}$ doses orallywas studied in attenuating electroshock-induced amnesia in rats. Extracts at $300 \mathrm{mg} / \mathrm{kg}$ dose produced significant memory retention, and the root parts were found to be more effective. In order to delineate the possible mechanism through which Clitoria ternatea elicited the anti-amnesic effects, its influence on central cholinergic activity was studied by estimating the acetylcholine content of the whole brain and acetylcholinesterase activity at different regions of the rat brain (cerebral cortex, midbrain, medulla oblongata and cerebellum). The results showed that Clitoria ternatea extracts increase rat brain acetylcholine content and acetyl cholinesterase activity, in a similar fashion to the standard cerebroprotective drug, Pyritinol [52].

Neonatal rat pups ( 7 days old) were intubated with either $50 \mathrm{mg} / \mathrm{kg}$ body weight or $100 \mathrm{mg} / \mathrm{kg}$ body weight of aqueous root extract of Clitoria ternatea (CTR) for 30 days. These rats were then subjected to open field, two compartment passive avoidance and spatial learning (T-Maze) tests (i) immediately after the treatment and (ii) 30 days after the treatment, along with age matched normal and saline control rats. Results showed no change in open field behaviour, but revealed improvement of retention and spatial learning performance at both time points of behavioural tests, indicating the memory enhancing property of CTR which implicates a permanent change in the brain of CTR treated rats [53-54].

\subsection{Colchicum balansae}

Methanol extracts of the seeds of Colchicum balansae were investigated for their in vitro cholinesterase (AChE and BChE)inhibitory activity at $200 \mu \mathrm{g} / \mathrm{ml}$, using ELISA microplate assay. Acetylcholinesterase inhibitory activity possessed by the methanolic extracts of Colchicum balansae seeds extract $(200 \mu \mathrm{g} / \mathrm{ml})$ was $10.90 \pm 1.17 \%$ and BChE inhibitory activity was $44.22 \pm 2.46 \%$ [55-56].

Many authors mentioned that Acetylcholinesterase inhibitors are the most effective approach to treat the cognitive symptoms of Alzheimer's disease. Although acetylcholinesterase inhibitors was the most widely used medication in Alzheimer's disease treatment, but some report propound that acetylcholinesterase inhibitors have inclement side effects such as anorexia, diarrhoea, fatigue, nausea, muscle cramps as well as gastrointestinal, cardio-respiratory, genitourinary and sleep disturbances. Accordingly, medical field search for new acetylcholinesterase inhibitors with higher efficacy from natural sources. Colchicum balansaeis one of the promising sources [55-58].

\subsection{Coriandrum sativum}

The effects of inhaled coriander volatile oil (1\% and 3\%, daily, for 21days) on spatial memory performance were assessed in an $A \beta(1-42)$ rat model of Alzheimer's disease. The $A \beta(1-42)$-treated rats exhibited the following: decrease of spontaneous alternations percentage within Y-maze task and increase of working memory errors, reference memory errors and time taken to consume all five baits within radial arm maze task. Exposure to coriander volatile oil significantly improved these parameters, suggesting positive effects on spatial memory formation. Assessments of oxidative stress markers in the hippocampal tissue of $A \beta(1-42)$-treated rats showed a significant increase of superoxide dismutase (SOD), lactate dehydrogenase (LDH) and a decrease of glutathione peroxidase (GPX) specific activities along with an elevation of malondialdehyde (MDA) level. Coriander volatile oil significantly decreased SOD and LDH specific activities, increased GPX specific activity and attenuated the increased MDA level. Also, DNA cleavage patterns were 
absent in the coriander rats, thus suggesting antiapoptotic activity of the volatile oil. Accordingly, the exposure to coriander volatile oil ameliorated $A \beta(1-42)$-induced spatial memory impairment by attenuation of the oxidative stress in the rat hippocampus [59].

The effects of fresh Coriandrum sativum leaves (CSL) on cognitive functions, total serum cholesterol levels and brain cholinesterase activity was investigated in mice. CSL $(5,10$ and 15\% w/w of diet) was fed orally with a specially prepared diet, for 45 days consecutively to mice. Elevated plus-maze and passive avoidance apparatus were used as the exteroceptive behavioral models for testing memory. Diazepam, scopolamine and ageing-induced amnesia were used as the interoceptive behavioral models. CSL (5, 10 and 15\% w/w of diet) produced a dose-dependent improvement in memory scores of young as well as aged mice. CSL also reversed successfully the memory deficits induced by scopolamine ( $0.4 \mathrm{mg} / \mathrm{kg}$, ip) and diazepam (1 mg/kg, ip). Brain cholinesterase activity and serum total cholesterol levels were considerably reduced by CSL administration in daily diets for 45 days [60-61].

The effects of inhaled coriander volatile oil (1\% and 3\%, daily, for 21 days) on spatial memory performance were assessed in an $A \beta(1-42)$ rat model of Alzheimer's disease. The $A \beta(1-42)$-treated rats exhibited the following: decrease of spontaneous alternations percentage within Y-maze task and increase of working memory errors, reference memory errors and time taken to consume all five baits within radial arm maze task. Exposure to coriander volatile oil significantly improved these parameters, suggesting positive effects on spatial memory formation. Assessments of oxidative stress markers in the hippocampal tissue of $A \beta(1-42)$-treated rats showed a significant increase of superoxide dismutase (SOD), lactate dehydrogenase (LDH) and a decrease of glutathione peroxidase (GPX) specific activities along with an elevation of malondialdehyde (MDA) level. Coriander volatile oil significantly decreased SOD and LDH specific activities, increased GPX specific activity and attenuated the increased MDA level. Also, DNA cleavage patterns were absent in the coriander rats, thus suggesting antiapoptotic activity of the volatile oil. Accordingly, the exposure to coriander volatile oil ameliorated $A \beta(1-42)$-induced spatial memory impairment by attenuation of the oxidative stress in the rat hippocampus [62].

The effect of Coriandrum sativum seed extract on learning was studied in second-generation mice. Ethanolic extract $(2 \%)$ of coriander was dissolved in sunflower oil as a vehicle and injected $(100 \mathrm{mg} / \mathrm{kg}$ intraperitoneal)to mother mice during breastfeeding for 25 days at 5-day intervals. After feeding the newborn mice, their learning was evaluated using a step-through passive avoidance task with $0.4 \mathrm{~mA}$ electric shock for 2 or 4 seconds. While coriander extract showed a negative effect in the short term (1 hour) after the training session, it potentiated the mice's learning in later assessments (24 hours post-training [ $\mathrm{P}=0.022]$ and 1 week post-training [ $\mathrm{P}=0.002]$ by a 4 -second shock). Low-dose caffeine $(25 \mathrm{mg} / \mathrm{kg}$ ip after training) improved the learning after 1 hour $(\mathrm{P}=0.024)$. No modification in the pain threshold was elicited by electric stimuli both in coriander and control groups [63-64].

\subsection{Cressa cretica}

The effects of Cressa cretica was evaluated in learning and memory in mice. Elevated plus maze and passive avoidance paradigm were utilized to test learning and memory. Two doses (200 and $400 \mathrm{mg} / \mathrm{kg}$, po) of ethanolic extract were administered for 28 successive days in separate group of animals. The dose of $400 \mathrm{mg} / \mathrm{kg}$ po, of Cressa cretica extract (CCE) significantly improved learning and memory of mice. Furthermore, this dose significantly reversed the amnesia induced by scopolamine $(0.4 \mathrm{mg} / \mathrm{kg}$, ip). To find out the mechanism by which CCE exerted nootropic activity, the effect of CCE on whole brain AChE activity was also estimated. CCE decreased whole brain acetyl cholinesterase activity and reduced whole brain MDA and NO levels. The antioxidant properties and the presence of flavonoids in Cressa cretica may be contributing to memory enhancement effect. Accordigly, Cressa cretica was a potent candidate for enhancing learning and memory and it would be beneficial for the treatment of amnesia and Alzheimer's disease [6569].

\subsection{Crocus sativus}

Alzheimer's disease was characterized pathologically by deposition of amyloid beta-peptide (Abeta) fibrils. Oxidation was thought to promote Abeta fibril formation and deposition. To identify agents inhibiting the pathogenesis of Alzheimer's disease, the antioxidant properties of extract of Crocus sativus stigmas and its effect on Abeta(1-40) fibrillogenesis was investigated in vtro. The antioxidant properties were determined by measuring the ferric-reducing antioxidant power and Trolox-equivalent antioxidant capacity, while its effects on Abeta-aggregation and fibrillogenesis were studied by thioflavine T-based fluorescence assay and by DNA binding shift assay. The water: methanol (50:50, $\mathrm{v} / \mathrm{v}$ ) extract ofCrocus sativus stigmas possessed good antioxidant properties, higher than those of tomatoes and carrots, and inhibited Abeta fibrillogenesis in a concentration and time-dependent manner. The main carotenoid constituent (trans-crocin-4) the digentibiosyl ester of crocetin, inhibited Abeta fibrillogenesis at lower concentrations than dimethylcrocetin, revealing that the action of the carotenoid was enhanced by the presence of the sugars. The result 
suggested the possible use of Crocus sativus stigma constituents for inhibition of aggregation and deposition of Abeta in the human brain [70].

Inhibitors of acetylcholine breakdown by acetylcholinesterase (AChE) constituted the main therapeutic modality for Alzheimer's disease. The inhibition of AChE activity of saffron extract and its constituents was studied by in vitro enzymatic and molecular docking studies. Saffron extract showed moderate AChE inhibitory activity (up to 30\%), but $\mathrm{IC}_{50}$ values of crocetin, dimethylcrocetin, and safranal were $96.33,107.1$, and $21.09 \mu \mathrm{M}$, respectively. Kinetic analysis showed mixed-type inhibition, which was verified by in silico docking studies. Safranal interacted only with the binding site of the AChE, but crocetin and dimethylcrocetin bind simultaneously to the catalytic and peripheral anionic sites [71].

The efficacy of Crocus sativus was studied in the treatment of patients with mild-to-moderate Alzheimer's disease. Fiftyfour Persian adults, 55 years of age or older were participated in a 22-week, double-blind study of parallel groups of patients with AD. The main efficacy measures were the change in the Alzheimer's Disease Assessment Scale-cognitive subscale and Clinical Dementia Rating Scale-Sums of Boxes scores compared with baseline. Adverse events (AEs). Participants were randomly assigned to receive a capsule saffron $30 \mathrm{mg} /$ day (15 mg twice per day) or donepezil 10 $\mathrm{mg} /$ day (5 mg twice per day). Saffron at this dose was found to be effective similar to donepezil in the treatment of mildto-moderate AD after 22 weeks. The frequency of AEs was similar between saffron extract and donepezil groups with the exception of vomiting, which occurred significantly more frequently in the donepezil group [72].

The recent behavioural and electrophysiological studies have demonstrated that saffron extract affected learning and memory in experimental animals. Saffron extract improved ethanol-induced impairments of learning behaviours in mice, and prevented ethanol-induced inhibition of hippocampal long-term potentiation, a form of activity-dependent synaptic plasticity that may underly learning and memory. Accordingly, saffron extract or its active constituents, crocetin and crocin, could be useful as a treatment for neurodegenerative disorders accompanying memory impairment [73].

Saffron extract was investigated in preventing D-galactose and $\mathrm{NaNO}_{2}$ induced memory impairment and improving learning and memory deficitsin amnestic mice. The learning and memory functions in ovariectomized mice were examined by the one way passive and active avoidance tests. In active avoidance test, training in amnestic treated (AT) and amnestic prophylaxis (AP) groups, was improved, there was a significant difference between them and the amnestic control (AC) group. In passive avoidance test, animal's step through latency, as an index for learning, in all test groups was significantly greater than control group. Total time spent in dark room (DS), which opposed the memory retention ability, in AC was significantly greater than AT group at 1 and 2 hours after full training, while there was no significant difference in this parameter between AP and AT [74].

The acute effects of an alcohol extract of Crocus sativus(CS-extract) were studied on learning and memory in step through (ST) and step down (SD) tests in normal, trained and memory-impaired mice. A single oral administration of CS-extract had no effects on memory registration, consolidation or retrieval in normal mice. CS-extract reduced the ethanol-induced impairment of memory registration both in ST and SD tests and the ethanol-induced impairment of memory retrieval in SD test. CS-extract decreased the motor activity (MA) and prolonged the sleeping time induced by hexobarbital [75].

Long-term potentiation (LTP) was thought as a generative mechanism underlying learning and memory via storing information in central nervous system. Electro-neurophysiological assay for LTP was generally used in screening the drugs that can facilitate learning and memory. Methanol extract of saffron (MES) being able to facilitate LTP-induction, and can antagonize the inhibiting effect of 30\% ethanol on LTP induction (30 pulses/60 Hz) [76].

The effects of Crocus sativus, and its active constituent crocin was evaluated on learning and memory loss and the induction of oxidative stress in the hippocampus by chronic stress. Rats were injected with saffron extract, crocin or vehicle over a period of 21 days while being exposed to chronic restraint stress $(6 \mathrm{~h} / \mathrm{day})$. Then, animals were trained and tested on a water-maze spatial memory task. They performed four trials per day for 5 consecutive days, and this was followed by a probe trial two days later. At the end of the behavioral testing, several parameters of oxidative stress in the hippocampus were measured. Treatment with saffron extractor crocin blocked the ability of chronic stress to impair spatial learning and memory retention. Relative to controls that received vehicle, stressed animals that received saffron extract or crocin had significantly higher levels of lipid peroxidation products, significantly higher activities of antioxidant enzymes including glutathione peroxidase, glutathione reductase and superoxide dismutase and significantly lower total antioxidant reactivity capacity. Crocin significantly decreased plasma levels of corticosterone, as measured after the end of stress. These results indicated that saffron and its active constituent crocin can prevent the 
impairment of learning and memory as well as the oxidative stress damage to the hippocampus induced by chronic stress [77].

The effect of aqueous extracts of saffron was investigated in morphine-induced memory impairment. On the training trial, the mice were received an electric shock when the animals were entered into the dark compartment. Twenty-four and forty-eight hours later, the time latency for entering the dark compartment was recorded and defined as the retention trial. The mice were divided into (1) control, (2) morphine which received morphine before the training in the passive avoidance test, (3-5) three groups treated by 50,150 and $450 \mathrm{mg} / \mathrm{kg}$ of saffron extract before the training trial, and ( 6 and 7) the two other groups received 150 and $450 \mathrm{mg} / \mathrm{kg}$ of saffron extract before the retention trial. The time latency in morphine-treated group was lower than control $(\mathrm{p}<0.01)$. Treatment of the animals by 150 and $450 \mathrm{mg} / \mathrm{kg}$ of saffron extract before the training trial increased the time latency at 24 and 48 hours after the training trial $(\mathrm{p}<0.05$ and $\mathrm{p}<0.01)$. Administration of both 150 and $450 \mathrm{mg} / \mathrm{kg}$ of the extract before retention trials also increased the time latency $(\mathrm{p}<0.01)$. The results revealed that the saffron extract attenuated morphine-induced memory impairment [78-79].

\subsection{Cuminum cyminum}

The memory-enhancing and antistress activities of Cuminum cyminum were studied in rats. Antistress activity was evaluated by inducing stress via forced swimming and the urinary vanillylmandelic acid (VMA) and ascorbic acid were estimated as biomarkers. Memory-enhancing activity was studied by conditioned avoidance response using Cook's pole climbing apparatus in normal and scopolamine-induced amnestic rats. Daily administration of cumin at doses of 100 , 200 , and $300 \mathrm{mg} / \mathrm{kg} \mathrm{bw}, 1 \mathrm{~h}$ prior to induction of stress, it inhibited the stress-induced urinary biochemical changes in a dose-dependent manner without altering the levels in normal control groups. The cognition, as determined by the acquisition, retention, and recovery in rats, was observed to be dose-dependent. The extract also produced significant lipid peroxidation inhibition in comparison with known antioxidant ascorbic acid in both rat liver and brain [80-82].

\subsection{Cupressus sempervirens}

The dichloromethane, acetone, ethyl acetate, and methanol extracts of the cones and leaves of Cupressus sempervirens var. horizantalis (CSH) and var. pyramidalis (CSP) were screened for their inhibitory activity against acetylcholinesterase (AChE), butyrylcholinesterase (BChE), and tyrosinase (TYRO). The extracts displayed weak to moderate cholinesterase inhibition at $200 \mu \mathrm{g} / \mathrm{ml}$. The cone dichloromethane extract of CSP showed the highest inhibition (36.10 $\pm 1.45 \%)$ against AChE, while the best inhibition $(40.01 \pm 0.77 \%)$ against BChE was caused by the leaf acetone extract of $\mathrm{CSH}$ [83-84].

The antiacethylcholinesterase studyof Cupressus sempervirens essential oil was also investigated. It showed that essential oilinhibitory concentration ( $\mathrm{IC}_{50}$ ) was0.2837 $\pm 0.0115 \mathrm{mg} / \mathrm{ml}$ [85-86].

\subsection{Cymbopogon schoenanthus}

The acetylcholinesterase inhibitory activity of the essential oils from fresh leaves, dried leaves and rootsof Cymbopogon schoenanthus was investigated. The greatest acetylcholinesterase inhibitory activity ( $\mathrm{IC}_{50}=0.26 \pm 0.03 \mathrm{mg} / \mathrm{ml}$ ) was exhibited by the essential oil of the fresh leaves from the mountain region in southern Tunisia [87].

Aqueous extract, proanthocyanidin rich extract, and organic extracts of Cymbopogon schoenanthus shoots from three different locations in south Tunisia were screened for acetylcholinesterase inhibitory activity. The greatest acetylcholinesterase inhibitory activity $\left(\mathrm{IC}_{50}=0.23 \pm 0.04 \mathrm{mg} / \mathrm{ml}\right.$ ) was exhibited by the ethyl acetate and methanol extracts of the plants collected from the mountainous regionin Tunisia [88-89].

\subsection{Cyperus rotuntdus}

The effect of the extract and essential oil of Cyperus rotundus on memory dysfunction was studied in mice. Cognition was evaluated using the object recognition task that was composed of a square wooden open field box with different shape objects. The test was consisted of three sections: 15 min exploration, first trial for 12 min and second one for 5 min. In the second trial the difference in exploration between a previously seen object and novel one, was considered as an index of memory performance (recognition index). Memory deficit was induced by scopolamine $(0.5 \mathrm{mg} / \mathrm{kg}$ ) before injection of plant extracts and essential oil. Neither the hydroalcholic extracts (100, 200, $400 \mathrm{mg} / \mathrm{kg}) \mathrm{nor}$ the polyphenolic extract $(50,100,200 \mathrm{mg} / \mathrm{kg})$ and essential oil $(10,20,40 \mathrm{mg} / \mathrm{kg})$ of Cyperus rotundus produced significant improvement of memory dysfunction [90-91]. 


\subsection{Dalbergia sissoo}

The effect of ethanolic leaf extracts of Dalbergia sissoo (ELDS) on learning and memory activity was evaluatedin mice. ELDS was givenas300, 450 and $600 \mathrm{mg} / \mathrm{Kg}$ respectively. The effect of ethanolic leaf extract of Dalbergia sissoo was investigated in mice for memory enhancing activity using various experimental paradigms of learning and memory viz. Transfer latency (TL) on elevated plus maze and passive avoidance. For memory and learning activity vehicle/ extracts / STD drug administered daily for first seven days, on $8^{\text {th }}$ day dementia was induced by scopolamine. ELDS significantly enhanced the learning and memory activities against the scopolamine induced dementia and significant decrease in Acetylcholinesterase level in brain in animals. The memory enhanced activity as evidenced by learning and retrieval was due to cholinergic facilitatory effect in animals. The results indicated a possible memory enhancing action of Dalbergia sissoo which qualitatively comparable with that of piracetam [92-93].

\subsection{Daucus carota}

The effects of D. carota seeds was evaluated in memory in rats. The ethanolic extract of Daucus carota (DCE) was administered orally in three doses $(100,200$ and $400 \mathrm{mg} / \mathrm{kg}$ ) for seven successive days to different groups of young and aged rats. Elevated plus-maze, Hebb-Williams maze and hexagonal swimming pool were used as exteroceptive behavioral models for testing memory. Diazepam-, scopolamine- and aging-induced amnesia were used as interoceptive behavioral models. DCE (200 and $400 \mathrm{mg} / \mathrm{kg}$, po) induced significant improvement in memory of young and aged rats in elevated plus maze, Hebb Williams maze and hexagonal swimming pool. It also reversed the amnesia induced by scopolamine $(0.4 \mathrm{mg} / \mathrm{kg}$, ip) and diazepam $(1 \mathrm{mg} / \mathrm{kg}$, ip). The results clearly indicated that Daucus carota seeds is a promising therapy to improve memory especially in management of Alzheimer patients [56].The seeds which contain choline, and have been reported to inhibit brain cholinesterase activity, with a possibility to elevate the brain acetylcholine levels via increased synthesis of acetylcholine, which beneficial in cognitive dysfunctions [94-95].

The effects of Daucus carota seeds on cognitive functions, total serum cholesterol levels and brain cholinesterase activity were studied in mice. The ethanolic extract of Daucus carota seeds (DCE) was administered orally in three doses $(100,200,400 \mathrm{mg} / \mathrm{kg})$ for seven successive days to different groups of young and aged mice. Elevated plus maze and passive avoidance apparatus served as the exteroceptive behavioral models for testing memory. Diazepam-, scopolamine- and ageing-induced amnesia served as the interoceptive behavioral models. DCE (200, $400 \mathrm{mg} / \mathrm{kg}$, p.o.) showed significant improvement in memory scores of young and aged mice. The extent of memory improvement evoked by DCE was $23 \%$ at the dose of $200 \mathrm{mg} / \mathrm{kg}$ and $35 \%$ at the dose of $400 \mathrm{mg} / \mathrm{kg}$ in young mice using elevated plus maze. Significant improvements in memory scores were observed with the using passive avoidance apparatus and aged mice. DCE also reversed the amnesia induced by scopolamine $(0.4 \mathrm{mg} / \mathrm{kg}$, ip) and diazepam $(1 \mathrm{mg} / \mathrm{kg}$, ip). Daucus carota extract $(200,400 \mathrm{mg} / \mathrm{kg}$, po) reduced significantly the brain acetylcholinesterase activity and cholesterol levels in young and aged mice. The extent of inhibition of brain cholinesterase activity evoked by DCE at the dose of $400 \mathrm{mg} / \mathrm{kg}$ was $22 \%$ in young and $19 \%$ in aged mice. There was a remarkable reduction in total cholesterol level as well, to the extent of $23 \%$ in young and $21 \%$ in aged animals with this dose of DCE [96].

The effects of Daucus carota seeds was evaluated in memory in rats. The ethanolic extract of Daucus carota (DCE) was administered orally in three doses $(100,200$ and $400 \mathrm{mg} / \mathrm{kg})$ for seven successive days to different groups of young and aged rats. Elevated plus-maze, Hebb-Williams maze and hexagonal swimming pool were used as exteroceptive behavioral models for testing memory. Diazepam-, scopolamine- and aging-induced amnesia were used as interoceptive behavioral models. DCE (200 and $400 \mathrm{mg} / \mathrm{kg}$, po) induced significant improvement in memory of young and aged rats in elevated plus maze, Hebb Williams maze and hexagonal swimming pool. It also reversed the amnesia induced by scopolamine $(0.4 \mathrm{mg} / \mathrm{kg}$, ip) and diazepam $(1 \mathrm{mg} / \mathrm{kg}$, ip). The results clearly indicated that $D$. carota seeds isa promising therapy to improve memory especially in management of Alzheimer patients [97-98].

\subsection{Equisetum arvense}

The chronic administration of the hydroalcoholic extract of stems of Equisetum arvense (HAE) reversed the cognitive impairment in aged rats. Chronic administration of HAE at dose of $50 \mathrm{mg} / \mathrm{kg}$, ip, improved both short- and long-term retention of inhibitory avoidance task and ameliorated the cognitive performance in reference and working memory version of the Morris Water Maze. No differences were found between all three groups of young controls, aged controls and EHA-treated animals with regard to the open field and elevated plus maze tests. In vitro assays revealed that HAE diminished the thiobarbituric acid reactive substances as well as nitrite formation, but did not alter catalase activity. The authors concluded that the cognitive enhancement effects of the HAE may be attributed, at least in part, to it antioxidant action [99-100]. 


\subsection{Foeniculum vulgare}

The nootropic and anticholinesterase potential of Foeniculum vulgare was studied in mice. Methanolic extract of the whole plant of $F$. vulgare administered for eight successive days ameliorated the amnesic effect of scopolamine $(0.4$ $\mathrm{mg} / \mathrm{kg}$ ) and aging- induced memory deficits in mice. The passive avoidance paradigm was usedas exteroceptive behavioral model for assessing memory. F. vulgare extract increased step-down latency and acetylcholinesterase inhibition in mice significantly. The authors postulated that $F$. vulgare can be employed in treatment of cognitive disorders such as dementia and Alzheimer's disease [101]. The nootropic and anticholinesterase potential of Foeniculum vulgare was studied in mice. Methanolic extract of the whole plant of $F$. vulgare administered for eight successive days ameliorated the amnesic effect of scopolamine $(0.4 \mathrm{mg} / \mathrm{kg})$ and aging-induced memory deficits in mice. The passive avoidance paradigm was used as exteroceptive behavioral model for assessing memory. $F$. vulgare extract increased step-down latency and acetylcholinesterase inhibition in mice significantly. The authors postulated that $F$. vulgare can be employed in treatment of cognitive disorders such as dementia and Alzheimer's disease [102-103].

\subsection{Fumaria officinalis}

F. officinalis appeared the most potent $\mathrm{AChE}$ acetylcholinesterase inhibitors among many Fumaria species, on a plant dry weight basis (IC50 $=4.7 \pm 0.2 \mathrm{mg}$ dry weight $/ \mathrm{ml}$ ), acetylcholinesterase inhibitory effects were correlated to the amount of protopine contained in $1 \mathrm{~g}$ of complex alkaloid isolated from the species [104].

Isoquinoline alkaloids isolated from aerial parts of Fumaria officinalis were evaluated for their biological activities related to Alzheimer's disease. Parfumidine and sinactine exhibited potent prolyl oligopeptidase (POP) inhibition activities (IC $5099 \pm 5$ and $53 \pm 2 \mu \mathrm{M}$, respectively) [105-106].

\subsection{Fumaria parviflora}

The chloroform: methanol [1:1] extracts of a number of the plant species belonging to eight families, including Fumaria parviflora, were screened for their anticholinesterase activity on acetyl cholinesterase [AChE] and butyrylcholinesterase [BChE] enzymes by in vitro at $10 \mathrm{microg} / \mathrm{ml}$ and $1 \mathrm{mg} / \mathrm{ml}$ concentrations. Among the screened extracts, all of the Fumaria extracts displayed highly potent inhibition against both of the enzymes at $1 \mathrm{mg} / \mathrm{ml}$ concentration compared to the standard [107-108].

\subsection{Glycyrrhiza glabra}

The deposition of senile plaque that is contributed mainly by amyloid- $\beta(A \beta)$, whose production is initiated by beta-site amyloid precursor protein (APP)-cleaving enzyme 1 (BACE1) is one of the typical hallmarks of Alzheimer's disease. Inhibition of BACE1 is thereby is an attractive strategy for anti- Alzheimer's disease drug discovery. The natural product 2,2',4'-trihydroxychalcone (TDC) from Glycyrrhiza glabra functioned as a specific non-competitive inhibitor against BACE1 enzyme, and potently repressed $\beta$-cleavage of APP and production of A $\beta$ in human embryo kidney cells. The amelioration ability of this compound against the in vivo memory impairment was further evaluated by APP-PS1 double transgenic mice model. $9 \mathrm{mg} / \mathrm{kg} /$ day of TDC decreased $\mathrm{A} \beta$ production and $\mathrm{A} \beta$ plaque formation, and efficiently improve the memory impairment based on Morris water maze test [109].

The effect of Glycyrrhiza glabra root extract(75, 150 and $300 \mathrm{mg} / \mathrm{kg}$ for 2 weeks)was evaluated on learning and memory in three months old male rats. Elevated plus-maze and Morris water maze tests were conducted to evaluate the learning and memory parameters as exteroceptive behavioral model and Diazepam induced amnesia as interoceptive behavioral model. The aqueous extract of root of Glycyrrhiza glabra showed improvement in learning and memory in a dose dependent manner. However, $150 \mathrm{mg} / \mathrm{kg}$ dose significantly $(\mathrm{p}<0.01)$ enhanced learning and memory [110-111].

The beneficial effects of aqueous extract of Glycyrrhiza glabra root extract $(75,150,225$, and $300 \mathrm{mg} / \mathrm{kg}$, for six successive weeks ) on learning and memory were studied in 1-month-old male Wistar albino rats using the elevated plus maze, Hebb-William maze, and Morris water maze tests as exteroceptive behavioral model andDiazepam-induced amnesia as interoceptive behavioral model. Results revealed that all the doses of aqueous root extract of Glycyrrhiza glabra significantly enhanced the memory; the doses 150 and $225 \mathrm{mg} / \mathrm{kg}$, possessed significant $(\mathrm{P}<0.01)$ enhancement in learning and memory. Furthermore, diazepam-induced amnesia was reversed by the aqueous root extract of Glycyrrhiza glabra (150 and $225 \mathrm{mg} / \mathrm{kg}$, po) [112].

The effects of aqueous extract of Glycyrrhiza glabra (75, 150 and $300 \mathrm{mg} / \mathrm{kg}$ po for 7 successive days)on learning and memory was also evaluated in mice. Elevated plus-maze and passive avoidance paradigm were employed to test learning and memory. The dose of $150 \mathrm{mg} / \mathrm{kg}$ of the aqueous extract of liquorice significantly improved learning and 
memory of mice. This dose also significantly reversed the amnesia induced by diazepam (1 mg/kg ip) and scopolamine $(0.4 \mathrm{mg} / \mathrm{kg}$ ip) [113].

The dose of $150 \mathrm{mg} / \mathrm{kg}$ of the aqueous extract of Glycyrrhiza glabrafor 7 successive days, significantly improved learning and memory of mice and reversed the amnesia induced by diazepam (1 mg/kg p), scopolamine $(0.4 \mathrm{mg} / \mathrm{kg} \mathrm{ip})$, and ethanol (1 g/kg ip) [114].

The effects of Glycyrrhiza glabra on learning and memory were evaluated using object recognition task (ORT) and elevated plus maze (EPM) models in mice. One dose level of aqueous liquorice extract $400 \mathrm{mg} / \mathrm{kg}$ poand two doses levels of Glabridin rich extract $5 \mathrm{mg} / \mathrm{kg}$ and $10 \mathrm{mg} / \mathrm{kg}$ were administered orally in separate groups of animals. aqueous liquorice extract and Glabridin $10 \mathrm{mg} / \mathrm{kg}$ treatment significantly improved learning and memory of mice by reversing the amnesia induced by scopolamine hydrobromide (2mg/kg, ip) and Diazepam (1mg/kg, ip) [115].

The effect of glabridin isolated from the roots of Glycyrrhiza glabra was investigated on cognitive functions and cholinesterase activity in mice. Glabridin (1, 2 and $4 \mathrm{mg} / \mathrm{kg}$, po) was administered daily for 3 successive days to mice. The higher doses ( 2 and $4 \mathrm{mg} / \mathrm{kg}$ po) of glabridin significantly antagonized the amnesia induced by scopolamine $(0.5$ $\mathrm{mg} / \mathrm{kg}$ ip)in both the elevated plus maze test and passive avoidance test. Glabridin ( 2 and $4 \mathrm{mg} / \mathrm{kg}$ po) also remarkably reduced the brain cholinesterase activity in mice compared to the control group [116].

The effect of Glycyrrhiza glabra oral supplementation was evaluated on the mental intelligence and memory function of the male students. Glycyrrhiza glabra tablets were formulated from the crude powder prepared from roots and subjected to dose standardization process and found suitable without any side effects. 123 students were divided into two group, treatment (1 tablet two times/ day) and placebo control (received starch powder)for the period of 60 days. Each group was further subdivided into two, based on low and high intelligence percentage in order to avoid biasness. Evaluation of improvement was judge by using NVIT (Non Verbal Intelligence Test) and memory test score before the start and at the end of treatment period and scored them accordingly into poor, moderate, good and, very good and expressed in percentage. The overall NVIT results indicated that oral consumption of Glycyrrhiza glabra tablets twice a day improved the intelligence level among the student compared to placebo treatment [117-118].

\subsection{Gossypium species}

The acetylcholinesterase (AChE) inhibition of a standardized extract from the flowers of Gossypium herbaceam (GHE) as well as the protective effects to PC12 cells against cytotoxicity induced by tertiary butyl hydroperoxide (tBHP)were investigated using in vitro assays. The results revealed that GHE exhibited certain activities against AChE and also is an efficient free radical scavenger, which may be helpful in preventing or alleviating patients suffering from Alzheimer's disease [119].

The protective effect of Gossypium herbaceam extracts (GHE) on learning and memory impairment associated with aging were examined in vivo using Morris water maze and step through task. Furthermore, the antioxidant activity and neuroprotective effect of GHE was investigated histochemically and biochemically. The results showed that oral administration with GHE at the doses of 35, 70, and $140 \mathrm{mg} / \mathrm{kg}$ improved the learning and memory impairment in aged rats. It also afforded a beneficial action on eradication of free radicals without influence on the activity of glutathione peroxidase and superoxide dismutase. GHE treatment enhanced the expression levels of nerve growth factor. The proliferation of neural progenitor cells was elevated in hippocampus after the treatment [120-121].

\subsection{Haplophyllum species}

The oil showed weakly acetylcholinesterase (AChE) inhibitory activity, compared to standard substances, whereas no inhibition on butyrylcholinesterase (BuChE) activity was observed(51). The inhibitory activity of acetyl cholinestrase was mainly accumulated in the chloforom and ethyl acetate fractions of different parts extracts of $H$. tuberculatum. The most active was the stem ethyl acetate fraction with an inhibitory effect of $79 \%$ and $\mathrm{IC}_{50}$ of $0.45 \mu \mathrm{g} / \mathrm{ml}$. Other fractions possessed an inhibitory effect at arrange between $70-77 \%$ [122-123].

\subsection{Hibiscus rosa sinensis}

An aqueous extract of Hibiscus rosa sinensis showed 62.02\% \pm 0.03 (SEM) inhibitory activity against AChE and $57.83 \% \pm 0.05$ (SEM) inhibitory activity against BUChE enzymes respectively. Accordingly, Hibiscus rosa sinensis could beuseful in improving memory [124]. 
The ethyl acetate soluble fraction of the methanol extract of of Hibiscus rosa sinensis (EASF) attenuated amnesia induced by scopolamine and aging. The discrimination index (DI) was significantly decreased in the aged and scopolamine group in object recognition test (ORT). Pretreatment with EASF significantly increased the DI. In passive avoidance test (PAT), scopolamine-treated mice exhibited significantly shorter step-down latencies (SDL). EASF treatment showed a significant increase in SDL in young, aged as well as in scopolamine-treated animals. The biochemical analysis of brain revealed that scopolamine treatment increased lipid peroxidation and decreased levels of superoxide dismutase (SOD) and glutathione reductase (GSH). Administration of extract significantly reduced LPO and reversed the decrease in brain SOD and GSH levels. The administration of Hibiscus rosa sinensis improved memory in amnesic mice and prevented the oxidative stress associated with scopolamine. This effect could be attributed to augmentation of cellular antioxidants [125].

An aqueous extract of Hibiscus rosa sinensis showed 62.02\% \pm 0.03 (SEM) inhibitory activity against AChE and $57.83 \% \pm 0.05$ (SEM) inhibitory activity against BUChE enzymes respectively. Accordingly, Hibiscus rosa sinensis could be useful in improving memory and other cognitive function associated with the cholinergic system [126-127].

\subsection{Hibiscus sabdariffa}

The nootropic acitivity of calyces of Hibiscus sabdariffa was studied in mice using elevated plus maze and passive avoidance paradigm to evaluate learning and memory parameters. The aqueous extracts of calyces of Hibiscus sabdariffa (100 and $200 \mathrm{mg} / \mathrm{kg}$, po) significantly attenuated amnestic deficits induced by scopolamine (0.4 mg/kg, ip) and natural aging. Hibiscus sabdariffa(100 and $200 \mathrm{mg} / \mathrm{kg})$ decreased the transfer latencies and in-creased step down latencies significantly in the aged mice and scopolamine induced amnesic mice as compared with Piracetam (200 mg/kg, ip). Acetylcholinesterase activity in the whole brain was significantly decreased in mice which could be indicated to the underlying mechanism of action [128-129].

\subsection{Hypericum triquetrifolium}

The crude methanolic extract of the aerial parts of $H$. triquetrifolium was examined for its potential activity in counteracting and preventing cognition impairment caused by acute and chronic restrain stress in rats. $H$. triquetrifolium methanolic extracts were administrated intraperitoneally $(50 \mathrm{mg} / \mathrm{Kg}$ ). Rats were tested for spatial memory in radial arm water maze test. Results revealed that chronic psychosocial stress impairs short term memory. Acute stress also impairs both short term memory and long term memory. Chronic H. triquetrifolium extract administration prevented stress induced memory impairment in both chronic and acute stressed rats which is confirmed by the correction of stress-induced reduction in BDNF protein levels especially in the hippocampal area of brain [130-131].

\subsection{Juglans regia}

In vitro neuroprotective effects of the leaf and fruit extracts of Juglans regia were studied through enzymes linked to Alzheimer's disease and antioxidant activity. Extracts of J. regia fruits and leaves exhibited low inhibition of butyrylcholinesterase, and it possessed no significant effect on acetylcholinesterase [132].

The effects of walnuts on learning and memory was studied in male rats. Walnut was given orally to rats for a period of 28days. Memory function in rats was assessed by elevated plus maze (EPM) and radial arm maze (RAM). A significant improvement in learning and memory of walnut treated rats compared to controls was observed. Analysis of brain monoamines exhibited enhanced serotonergic levels in rat brain following oral intake of walnuts [133].

The effects of walnut supplementation on motor and cognitive ability were investigated in aged rats. The motor testing showed that the $2 \%$ walnut diet improved performance on rod walking, while the $6 \%$ walnut diet improved performance on the medium plank walk; the higher dose of the $9 \%$ walnut diet did not improve psychomotor performance and on the large plank actually impaired performance. All of the walnut diets improved working memory in the Morris water maze, but the 9\% diet showed impaired reference memory [134].

The effects of walnut consumption by mothers during pregnancy and lactation on learning and memory in adult offsprings were studied in rats. The results showed that there was a significant difference in learning and memory of rat offsprings between experimental and control groups [135-136].

\subsection{Juniperus communis}

The effects of inhaled juniper volatile oil (1\% and 3\%, daily, for 21 days) on spatial memory performance were assessed in an $A \beta(1-42)$ rat model of Alzheimer's disease. The $A \beta(1-42)$-treated rats exhibited decrease of spontaneous 
alternations percentage within Y-maze task and increase of working memory and reference memory errors within radial arm maze task [137].

The effects of inhaled juniper volatile oil (1\% and 3\%, daily, for 21 days) on spatial memory performance were assessed in an $A \beta(1-42)$ rat model of Alzheimer's disease. The $A \beta(1-42)$-treated rats exhibited decrease of spontaneous alternations percentage within Y-maze task and increase of working memory and reference memory errors within radial arm maze task [138-139].

\subsection{Lycium barbarum}

Lycium barbarum polysaccharides (LBP)decreased levels of serum AGE, hydroxyproline concentration in mouse skin and spontaneous motor activity in D galactose mouse aging model. On the other hand, lymphocyte proliferation and IL2 activity, learning and memory abilities and the SOD activity of erythrocytes, were enhanced [140-141].

The effects of Lycium barbarum polysaccharides on neuronal function, neurogenesis, and drug-induced learning and memory deficits were investigated in scopolamine -treated rats. Polysaccharides were administered via gastric perfusion for 2 weeks before the onset of subcutaneous scopolamine treatment and for further 4 weeks. Scopolamine and polysaccharides - treated rats spent significantly more time exploring the novel object or location in the recognition tasks and had significant shorter escape latency in the water maze. Scopolamine administration led to a decrease in Ki67- or DCX-immunoreactive cells in the dentate gyrus and damage of dendritic development of the new neurons; polysaccharides prevented these scopolamine -induced reductions in cell proliferation and neuroblast differentiation. Polysaccharides also protected scopolamine -induced loss of neuronal processes in DCX-immunoreactive neurons. Polysaccharides decreased the scopolamine -induced oxidative stress in hippocampus and reversed the ratio Bax/Bcl2 that increased after scopolamine treatment. However, polysaccharides didn't affected the decreased BDNF and increased AChE induced by scopolamine [142].

The standardized Lycium barbarum fruit juice (GoChi®, Free Life International, Phoenix, AZ, USA) at $120 \mathrm{ml} / \mathrm{day}$ (equivalent to at least $150 \mathrm{~g}$ of fresh fruit), was studied for 30 days in a randomized, double-blind, placebo-controlled clinical study in 60 older healthy adults to determine its effects on general well-being, and safety. GoChi group showed a significant increase in general feelings of well-being, such as fatigue and sleep, and showed a tendency for increased short-term memory and focus between pre- and postintervention. No adverse reactions, abnormal symptoms, or changes in body weight, blood pressure, pulse, visual acuity, urine, stool, or blood biochemistry were recorded [143].

\subsection{Mangifera indica}

The effect of Mangifera indica aqueous extract (10,50, and $100 \mathrm{mg} / \mathrm{kg}$ orally, for $12 \mathrm{months})$ and mangiferin (10 mg/kg, orally for 12 months) on behavioral outcomes of neurological function in spinocerebellar ataxia type 2 (SCA-2) was studied in transgenic mice. Locomotion (open-field), aversive memory (inhibitory avoidance) and declarative memory (object recognition) were used for evaluation. The possible cellular mechanisms was also evaluated on nerve grow factor (NGF) and tumor necrosis factor- $\alpha$ (TNF- $\alpha$ ) levels in the human glioblastoma cell line U138-MG supernatant. Mangifera indica aqueous extract administration did not affect the object recognition memory, but mangiferin did. The natural extract improved selectively the aversive memory in SCA- 2 mice, indicating that Mangifera indica aqueous extract can affect behavioral parameters regarding fear-related memory. Mangifera indica aqueous extract also induced a significant increase in supernatant levels of NGF and TNF- $\alpha$ in vitro in human U138-MG glioblastoma cells [144].

The cognitive enhancing effects of Mangifera indica fruit extract were studied in rat model of mild cognitive impairment. Male rats, were orally given the extract at doses of 12.5, 50, and $200 \mathrm{mg} / \mathrm{kg}$ for 2 weeks before and 1 week after the bilateral intracerebroventricular injection of a cholinergic neuronspecific neurotoxin (AF64A). Spatial memory, cholinergic neurons density, MDA level, and the activities of SOD, CAT, and GSH-Px enzymes in hippocampus were determined. The results showed that all doses of extract improved memory together with the decreased MDA level and increased SOD and GSH-Px enzymes activities. It also increased cholinergic neurons density in CA1 and CA3 of hippocampus at doses of 50 and $200 \mathrm{mg} / \mathrm{kg}$ bw [145].

The ethanolic extract of Mangifera indica fruit was evaluated in cognitive performances in mice (step down passive avoidance task and elevated plus maze task). Chronic treatment ( 7 days) of extract and vitamin $\mathrm{C}$ significantly ( $\mathrm{p}<0.05$ ) reversed the aging and scopolamine induced memory deficits in both paradigms [146].

The effect of systemic administration of Vimang on behavioural outcomes of neurological function was studied in rats. A single oral administration of Vimang produced an impairment of short and long-term retention of memory for aversive training when given either $1 \mathrm{~h}$ pre training or immediately post training, but not $8 \mathrm{~h}$ post training. Vimang did 
not affect open field behaviour or habituation. Accordingly, Vimang induced deficits of emotionally motivated memory without affecting non associative memory, locomotion, exploratory behaviour or anxiety [147-148].

\subsection{Matricaria chamomilla}

The effect of the hydroalcoholic extract of Matricaria chamomilla on memory was studied in a scopolamine-induced amnesia in rats. The extract reversed the scopolamine- induced decreasing of the spontaneous alternation in the Y-maze test and the scopolamine-induced increasing of the working and reference memory errors in the radial arm maze test. Furthermore, the scopolamine-induced alteration of the acetylcholinesterase activity and the oxidant- antioxidant balance in the rat hippocampus was recovered by the treatment with the extract. The extract also restored the scopolamine-decreased BDNF expression and increased IL1 $\beta$ expression in the rat hippocampus [149].

\subsection{Medicago sativa}

The neuroprotective effect of methanol extract of Medicago sativa on ischemia and reperfusion-induced cerebral injury was investigated in mice. Pre-treatment with Medicago sativa methanolic extract (100 or $200 \mathrm{mg} / \mathrm{kg}$, orally) markedly reduced cerebral infarct size, xanthine oxidase, $0-2$ production, thiobarbituric acid-reactive substance, and significantly restored reduced glutathione, superoxide dismutase and total tissue sulfhydryl levels and attenuated impairment in short-term memory and motor coordination. The extract directly scavenged free radicals generated against a stable radical 1,1- diphenyl-2-picrylhydrazyl and $0-2$ generated in phenazine methosulphate- nicotinamide adenine dinucleotide systems, and also inhibited XD/XO conversion and resultant O-2 production [150].

A combined molecular docking and network analysis were carried out to study the mechanisms of the beneficial effect of Medicago sativa in neurodegenerative diseases. Medicago sativa showed memory improving activities and central nervous protective effects, which attributed to its triterpenesaponins contents [151-152].

\subsection{Melilotus officinalis}

The effect of Melilotus officinalis extract in Alzheimer disease was studied, regarding its possible role as antiinflammatory, anti-oxidant agent and its effect on the expression of many genes including DAXX, NFkB and VEGF. The results revealed that the extract caused significant decreased the expression of Daxx, $N f k b$ and Vegf genes in the sporadic Alzheimer disease rat's model compared to the streptozotocin (STZ)- induced rats. Furthermore, no significant changes were seen in swimming distance and time for finding the hidden platform in the extract- treated compared to the STZinduced group. No significant changes were observed in the memory level among treated and untreated groups [153154].

\subsection{Melissa officinalis}

The effect of subchronic administration of a $50 \%$ ethanol extract of Melissa officinalis leaves $(200 \mathrm{mg} / \mathrm{kg}$, po) compared with rosmarinic acid (RA, $10 \mathrm{mg} / \mathrm{kg}$, po) and huperzine A (HU, $0.5 \mathrm{mg} / \mathrm{kg}$, po) on behavioral and cognitive responses were studied in scopolamine-induced rats. Melissa officinalis extract and huperzine, but not rosmarinic acid, showed an improvement in long-term memory. The results were in line with mRNA levels, since Melissa officinalis decreased acetylcholinesterase mRNA level by 52\% in the cortex and caused a strong significant inhibition of beta-secretase 1 mRNA transcription (64\% in the frontal cortex; $50 \%$ in the hippocampus). However, the extract produced insignificant inhibition of acetylcholinesterase activity in the frontal cortex [155].

The role ofMelissa officinalis $(25 \mathrm{mg} / \mathrm{kg})$ on ethanol state-dependent learning was studied in adult nicotine-treated male mice. Melissa officinalis extract $(25 \mathrm{mg} / \mathrm{kg})$ ameliorated the decreasing effects of pre training ethanol $(0.25,1 \mathrm{~g} / \mathrm{kg})$ and nicotine $(0.1 \mathrm{mg} / \mathrm{kg})$ on step down latency (SDL) [156].

The extract of Melissa officinalis was capable of inhibiting the acetylcholinesterase enzyme, in a time and dosedependent manner. Activity of the extract at $10 \mathrm{~min}$ was estimated as $1.72 \pm 0.16$ microg equivalents of physostigmine/mg of the extract. The contents of the most potent fraction were identified as cis- and trans-rosmarinic acid isomers and a rosmarinic acid [157].

The cognitive and mood effects of single doses of the most cholinergically active Melissa officinalis dried leaf $(600,1000$, and $1600 \mathrm{mg}$ of encapsulated dried leaf, at 7-day intervals) were assessed in a randomized, placebo-controlled, doubleblind. Cognitive performance and mood were assessed before intiation of the treatment and at 1, 3, and $6 \mathrm{~h}$ post treatment. The most notable cognitive and mood effects were included improvement memory performance and increase (calmness) at all post treatment time points for the highest $(1600 \mathrm{mg})$ dose. However, decrements in the speed 
of timed memory task performance and on a rapid visual information-processing task increased with decreasing dose [158].

A placebo-controlled, double-blind, balanced-crossover study was performed to determine the effects of Melissa officinalis [single doses of 300,600 and $900 \mathrm{mg}$ of a standardised extract of Melissa officinalis (Pharmaton)] on cognition and mood in healthy humans. Melissa extract caused time- and dose-specific reductions in both secondary memory and working memory factors. Self-rated (calmness), was elevated at the earliest time points by the lowest dose, whilst, alertness was significantly reduced at all time points following the highest dose. Both nicotinic and muscarinic binding were found to be low [159].

Four month, parallel group, placebo controlled trial was carried out to evaluate the efficacy and safety of Melissa officinalis extract (60 drops/day) in patients with mild to moderate Alzheimer's disease. Melissa officinalis extract produced a significantly better outcome on cognitive function than placebo [Alzheimer's disease assessment scale (ADAS-cog): $\mathrm{P}=0.01$ and clinical dementia rating (CDR): $\mathrm{P}<0.0001]$. There were no significant differences in the side effects except agitation, which was more common in the placebo group $(\mathrm{P}=0.03)[160]$.

\subsection{Morus alba}

Ethanolic extract of leaves of Morus alba attenuated motor deficit, declined memory, depression and anxiety-like behavior in rats with high cholesterol diet (HCD), compared to that noticed in untreated HCD rats [161].

Mulberry leaf extract protected hippocampal neurons against amyloid beta-peptide (1-42)-induced cell death in a concentration-dependent manner. Amyloid beta-peptide (1-42) played an important role in the etiology of Alzheimer's disease. Accordingly, mulberry leaf extract provided a natural treatment for Alzheimer's disease through inhibition of amyloid beta-peptide (1-42) fibril formation and attenuation of amyloid beta-peptide (1-42)-induced neurotoxicity [162].

\subsection{Morus nigra}

The effect of Morus nigra leaf extract (50 or $100 \mathrm{mg} / \mathrm{kg}$, orally, daily for 8 weeks) was studied on cognitive impairment and oxidative stress status of D-galactose-induced aging mice. Behavioral responses were evaluated with Morris water maze. Activities of antioxidant enzymes and levels of MDA were assayed in serum, brain, and liver. Morus nigra significantly improved learning dysfunctions $(\mathrm{P}<0.01)$, increased memory retention $(\mathrm{P}<0.01)$, reduced MDA levels $(\mathrm{P}<$ 0.05), and elevated SOD, GPx, and CAT activities $(\mathrm{P}<0.05)$ compared with the D-galactose group [163].

\subsection{Nicotiana tabacum}

Nicotiana tabacum extract show anti-Alzheimer's activity and improved memory(61). [3H]acetylcholine and $[3 \mathrm{H}]$ nicotine were used to label nicotinic cholinergic binding sites in cerebral cortical tissues obtained at autopsy from patients with Alzheimer's disease and from matched controls. A consistent and severe loss of nicotinic receptors was found in Alzheimer's disease [164].

Rats with lesion associated with neurochemical and cellular changes resembling those seen in human Alzheimer's disease, were treated with nicotine $(0.1,0.2,0.4 \mathrm{mg} / \mathrm{kg})$. Treated rats showed an enhanced locomotor response after injections of nicotine compared with sham operated or un-operated controls [165].

A double-blind placebo-controlled trial was conducted to determine the effects of sustained nicotine administration on behavior, cognition, and physiology. The results revealed improved learning during the nicotine treatment, persisted throughout washout. Memory, behavior, and global cognition were not significantly affected. Sustained administration of nicotine appeared to be safe, although sleep was significantly decreased [166].

\subsection{Nigella sativa}

Feeding of hydroalcoholic extract of Nigella sativa during neonatal and juvenile growth possessed positive effects on learning and memory(155). The total extract of Nigella sativa and its separated fractions was studied in vitro. The total extract of Nigella sativa $(10,100,250,500,750$ and $1000 \mu \mathrm{g} / \mathrm{ml})$ and all the separated fractions inhibited AChE enzyme in a concentration-dependent manner(156). Nigella sativa increased 5-HT levels in brain and improved learning memory in rats [167].

The effects of Nigella sativa hydro alcoholic extract on learning, memory and brain tissues oxidative damage were investigated in penthylenetetrazole (PTZ) - induced repeated seizures. Seizure scores were lower in PTZ - NS + extract 
200 and $400 \mathrm{mg} / \mathrm{kg}$, and the seizure onset latencies were higher than $\mathrm{PTZ}$ group $(\mathrm{P}<0.05$ and $\mathrm{P}<0.01)$. In Morris water maze, the time spent in target quadrant by PTZ group was lower than control group $(\mathrm{P}<0.05)$; while, $400 \mathrm{mg} / \mathrm{kg}$ of the extract increased it significantly $(\mathrm{P}<0.01)$. In the passive avoidance test, delay time to enter the dark by PTZ group was lower than control at 1 and 24 hours after training $(\mathrm{P}<0.01-\mathrm{P}<0.001)$, while, $400 \mathrm{mg} / \mathrm{Kg}$ of the extract increased it significantly $(\mathrm{P}<0.05)$. The total thiol concentration in hippocampal and cortical tissues of PTZ group was reduced while, MDA concentration was higher than control $(\mathrm{P}<0.05-\mathrm{P}<0.001)$. Administration of the extract increased the total thiol and decreased the MDA concentrations significantly $(\mathrm{P}<0.01-\mathrm{P}<0.001)$. According to the results, the hydro-alcoholic extract possessed beneficial effects on learning and memory impairments in repeated seizures model [168].

The effects of Nigella sativa hydroalcoholic extract on lipopolysaccharide (LPS)-induced learning and memory impairments, hippocampal cytokine levels, and brain tissues oxidative damage were investigated in rats. In Morris water maze test, LPS increased the escape latency and traveled path compared to control group, whereas all doses of the extract decreased them compared to LPS group. In passive avoidance test, the latency to enter the dark compartment in LPS group was shorter than control group while in all treated groups, it was longer than LPS group. LPS increased TNF- $\alpha$, IL-6, malondialdehyde (MDA), and nitric oxide (NO) metabolites, and decreased thiol content, superoxide dismutase (SOD), and catalase (CAT) in the hippocampal tissues compared to control group, while the extract decreased MDA and NO metabolites and increased thiol content, SOD, and CAT compared to LPS group. The results indicated that the hydroalcoholic extract of Nigella sativa improved the LPS-induced learning and memory impairments in rats by improving hippocampal cytokine levels and brain tissues oxidative damage [169].

The hydro-alcohol extract of Nigella sativa also protected against synaptic plasticity and spatial learning and memory impairment induced by lipopolysaccharide in rats [170].

The effects of hydroalcoholic extract of Nigella sativa seeds and thymoquinone on learning and memory deficits, hippocampal acetylcholine esterase (AChE) activity, and markers of redox status, were studied following cerebral hypoperfusion in rats. Cerebral hypoperfusion was induced by permanent occlusion of bilateral common carotid arteries. Treatments were administered for 10 days three days before and seven days after ligation. Spatial learning and memory deficits were investigated using the Morris water maze (MWM) task. Occlusion of bilateral common carotid arteries produced significant learning and memory deficits as evidenced by increased latency time to reach the hidden platform, increased swimming time, and decreased time spent in the target quadrant in the probe trial in the MWM task. There was also a significant increase in the lipid peroxidation level and AChE activity, and a significant decrease in SOD activity in the hippocampal portion of hypoperfused rats. Treatment with the extract $(400 \mathrm{mg} / \mathrm{kg} / \mathrm{day}) \mathrm{and}$ thymoquinone $(40 \mathrm{mg} / \mathrm{kg} /$ day), significantly $(\mathrm{P}<0.001)$ prevented learning and memory impairments and alleviated changes in the hippocampal lipid peroxide level and SOD and AChE activities [171].

The effects of hydroalcoholic extract of Nigella sativa on hypothyroidism-associated learning and memory impairment during neonatal and juvenile growth were studied in rats. Propylthiouracil exposure significantly increased the time latency in MWM test, while reduced the time spent in target quadrant, and decreased the latency for entering the dark compartment in passive avoidance test. These effects were associated with significant reduction in serum thyroxine levels and brain levels of thiol groups, and significant elevation in hippocampal MDA. Administration of $400 \mathrm{mg} / \mathrm{kg}$ Nigella sativa extract reduced the time latency, while increased the time spent in target quadrant compared to the propylthiouracil group in MWM test. Treatment with $100-400 \mathrm{mg} / \mathrm{kg}$ of Nigella sativa extract significantly increased the time latency for entering the dark compartment in passive avoidance test [172].

The effect of hydroalcoholic extract of Nigella sativa on memory performance and its possible mechanisms in was studied in scopolamine induced spatial memory impairment model using MWM test. Nigella sativa treated group showed a significantly shorter travel path and time latency compared to the active control receiving scopolamine. Acetycholinestrase activity in the Nigella sativa treated groups was lower than that in the scopolamine group. Pretreatment of the animals with Nigella sativa decreased the malondialdehyde concentration in hippocampal tissues and increased the thiol content compared to control group [173].

Nigella sativa methanol, n-hexane, and aqueous seed extracts were tested for their inhibitory activity against butyrylcholinesterase (BChE). All extracts showed inhibitory activity against BChE, with methanol seed extract possessed the highest inhibitory activity $\mathrm{IC}_{50}$ of $79.11 \pm 6.06 \mu \mathrm{g} / \mathrm{ml}[174]$.

A randomized placebo controlled study was designed to study the effects of Nigella sativa seed (500 mg capsule twice daily for nine weeks) on memory, attention and cognition in healthy elderly volunteers. Black seeds enhanced memory, attention and cognition and considered as a potential food supplement for the prevention of Alzheimer disease in 
elderly. The biochemical markers of cardiac, liver and kidney functions remained normal in Nigella sativa seed treatment group throughout the study period [175].

The effect of Nigella sativa on cognition in adolescent human males was examined at a boarding school in Bangladesh, besides its effect on mood and anxiety. Two groups of recruited volunteers, A and B, received capsule of $500 \mathrm{mg}$ placebo and $500 \mathrm{mg}$ Nigella sativa seed/day, for 4 weeks, respectively. The results indicated positive effect of Nigella sativa on the mood and anxiety after 4 weeks. Nigella sativa caused significant variation in immediate short-term recall. However, long-term free recall and long-term cued recall showed statistical differences between group A and B [176].

\subsection{Ocimum basilicum}

The neuroprotective effect of Ocimum basilicum leaf extract (200 and $400 \mathrm{mg} / \mathrm{kg}$, orally, once daily for 7 days) was studied following cerebral injury induced by bilateral common carotid artery occlusion followed by rep erfusion in mice. Cognitive outcomes and sensorimotor disturbances were evaluated with Morris Water Maze, Elevated Plus Maze and neurological severity score, respectively. Treatment with the extract resulted in marked improvement in memory and motor coordination. The extract also decreased cerebral infarct size and oxidative stress in mice. The extract contained high total phenol content, and possessed strong antioxidant effects [177].

The effects of Ocimum basilicum hydroalcoholic extract $(100,200,400$ and $800 \mathrm{mg} / \mathrm{kg}$, ip) on memory retention and retrieval of mice were studied using passive avoidance apparatus. In retention test, basil extract was administered immediately after receiving electric shock and in retrieval test it was administered 24 hours after receiving electric shock. The results showed that hydroalcoholic extract of Ocimum basilicum significantly $(\mathrm{P}<0.05)$ increased memory retention. The best response was achieved with $400 \mathrm{mg} / \mathrm{Kg}$ of the extract. Basil extract also significantly $(\mathrm{P}<0.05)$ increased memory retrieval and the best result was achieved with $400 \mathrm{mg} / \mathrm{kg}$ [178].

The anti-amnesic effect of Ocimum basilicum hydromethanol extracts was investigated using in vitro and in vivo models. Ocimum basilicum extract showed marked free radical scavenging, reducing power and AChE inhibition (IC50 $0.65 \pm 0.15 \mathrm{mg} / \mathrm{ml})$ activity. The in vivo studies showed that pre-treatment with Ocimum basilicum extract $(200$ and $400 \mathrm{mg} / \mathrm{kg}$, po reversed the memory deficit induced by scopolamine in mice, evident by significant $(\mathrm{P}<0.05)$ decrease in the transfer latency time and increase in step down latency in elevated plus maze and passive shock avoidance task, respectively. The extract also significantly reduced the brain AChE activity and oxidative stress. Histopathological examination of brain tissues displayed decrease in vacuolated cytoplasm and increase in pyramidal cells in hippocampal and cortical regions in animals pre-treated with the extract [179-180].

\subsection{Oxalis corniculata}

Different doses of Oxalis corniculata increased memory retention and retrieval significantly. The authors concluded that the memory retention and retrieval enhancement of Oxalis corniculata extract could be attributed to the presence of antioxidants such as flavonoids, coumarins, tocopherols and phenolic acids [181].

\section{Conclusion}

Alzheimer's disease is an age-related neurodegenerative disorder characterized by memory deficits. Various studies have been carried out to find therapeutic approaches for Alzheimer's disease. However, the proper treatment option is still not available. Natural therapy including herbs and medicinal plants has been used in the treatment of memory deficits such as dementia, amnesia, as well as Alzheimer's disease since a long time. In this paper. The sensitive contents and the mechanism of action of some of these plants were investigated. In this article, we have reviewed the detail about the medicinal plants with potential therapeutic values in $\mathrm{AD}$ with emphasis on their mechanisms of action, as promising therapeutic remedies because of their effectiveness and safety.

\section{Compliance with ethical standards}

\section{Acknowledgments}

We acknowledged the dean of Thi qar college of medicine, for the scientific support.

\section{Disclosure of conflict of interest}

The author confirm that this paper's content has no conflict of interests. 


\section{Funding}

The author received no fund from any source.

\section{References}

[1] Manoharan S, Essa MM, Vinoth A, Kowsalya R, Manimaran A, Selvasundaram R. Alzheimer's Disease and Medicinal Plants: An Overview. Adv Neurobiol 2016;12:95-105.

[2] Kumar A, Singh A, Ekavali. A review on Alzheimer's disease pathophysiology and its management: an update. Pharmacol Rep. 2015;67(2):195-203.

[3] Hampel H, Mesulam MM, Cuello AC, Farlow MR, Giacobini E, Grossberg GT, Khachaturian AS, Vergallo A, Cavedo E, Snyder PJ, Khachaturian ZS. The cholinergic system in the pathophysiology and treatment of Alzheimer's disease. Brain. 2018;141(7):1917-1933.

[4] Al-Snafi AE. Therapeutic properties of medicinal plants: a review of medicinal plants with central nervous effects (part 1). Int J of Pharmacology \& Toxicology. 2015;5(3): 177-192.

[5] Al-Snafi AE. Medicinal plants with central nervous effects (part 2): plant based review. IOSR Journal of Pharmacy. 2016; 6(8): 52-75.

[6] Al-Snafi AE,Talab TA, Majid WJ. Medicinal plants with central nervous activity - An overview (Part 1). IOSR Journal of pharmacy. 2019; 9(3): 52-102.

[7] Uddin MS, Al Mamun A, Kabir MT, Jakaria M, Mathew B, Barreto GE, Ashraf GM. Nootropic and Anti-Alzheimer's actions of medicinal plants: Molecular insight into therapeutic potential to alleviate Alzheimer's neuropathology. Mol Neurobiol. 2019;56(7):4925-4944.

[8] Bui TT, Nguyen TH. Natural product for the treatment of Alzheimer's disease. J Basic Clin Physiol Pharmacol 2017;28(5):413-423.

[9] Seo EJ, Fischer N, Efferth T. Phytochemicals as inhibitors of NF- $\kappa B$ for treatment of Alzheimer's disease. Pharmacol Res. 2018;129:262-273.

[10] Nabavi SM, Talarek S, Listos J, Nabavi SF, Devi KP, Roberto de Oliveira M, Tewari D, Argüelles S, Mehrzadi S, Hosseinzadeh A, D'onofrio G, Orhan IE, Sureda A, Xu S, Momtaz S, Farzaei MH. Phosphodiesterase inhibitors say NO to Alzheimer's disease. Food Chem Toxicol. 2019;134:110822.

[11] Perry EK, Pickering AT, Wang WW, Houghton PJ, Perry NS. Medicinal plants and Alzheimer's disease: from ethnobotany to phytotherapy. J Pharm Pharmacol. 1999;51(5):527-534.

[12] Amat N, Hoxur P, Ming D, Matsidik A, Kijjoa A, Upur H. Behavioral, neurochemical and neuroendocrine effects of Abnormal SavdaMunziq in the chronic stress mice. Evidence-Based Complementary and Alternative Medicine. $2012 ; 426757$.

[13] Al-Snafi AE. The pharmacologyof Anchusaitalica and Anchusa strigosa- A review. International Journal of Pharmacy and Pharmaceutical Sciences. 2014; 6(4): 7-10.

[14] George VK, George A, Kopcke B, Roemer E,m Bitzer J, Gruenwald J, Gehling M, tengku A, tengkuS, Torsten G. Aurones as selective pde inhibitors and their use in neurological conditions and disorders. Patent. 2009.

[15] Al-Snafi AE. The pharmacological importance of Antirrhinum majus - A review. Asian J of Pharm Sci \& Tech. 2015; 5(4): 313-320.

[16] Bhattacharya SK, Kumar A, Ghosal S. Effect of Bacopa monniera on animal models of Alzheimer's disease and perturbed central cholinergic markers of cognition in rats. Research Communications in Pharmacology and Toxicology. 1999; 4(3\&4):1-12.

[17] Ryan J, Croft K, Mori T, Wesnes K, Spong J, Downey L, Kure C, Lloyd J, Stough C. An examination of the effects of the antioxidant Pycnogenol ${ }^{\circledR}$ on cognitive performance, serum lipid profile, endocrinological and oxidative stress biomarkers in an elderly population. Journal of Psychopharmacology. 2008;22(5):553-562.

[18] Saraf MK, Prabhakar S, Pandhi P, Anand A. Bacopa monniera ameliorates amnesic effects of diazepam qualifying behavioural-molecula partitioning. Neuroscience. 2008; 155(2):476-484.

[19] Vohora D, Pal SN, Pillai KK. Protection from phenytoin-induced cognitive deficit by Bacopa monniera, a reputed Indian nootropic plant. J Ethnopharmacol. 2000; 71: 383-390. 
[20] Morgan A, Stevens J. Does Bacopa monnieri improve memory performance in older persons? Results of a randomized, placebo-controlled, double-blind trial. The Journal of Alternative and Complementary Medicine. 2010;16(7):753-759.

[21] Stough C, Lloyd J, Clarke J, Downey LA, Hutchison CW, Rodgers T, Nathan PJ. The chronic effects of an extract of Bacopa monniera (Brahmi) on cognitive function in healthy human subjects. Psychopharmacology. 2001; 156:481-484.

[22] Roodenrys S, Booth D, Bulzomi S, Phipps A, Micallef C, Smoker J. Chronic effects of Brahmi (Bacopa monnieri) on human memory. Neuropsychopharmacology. 2002; 27(2):279-281.

[23] Al-Snafi AE.The pharmacology of Bacopa monniera. A review. International Journal of Pharma Sciences and Research. 2013; 4(12): 154-159.

[24] Karaka FB, Karaka A, kun HC, Turker AC. Effects of common daisy (Bellis perennis L.) aqueous extracts on anxietylike behaviour and spatial memory performance in Wistar albino rats. African Journal of Pharmacy and Pharmacology. 2011; 5(11):1378-1388.

[25] Al-Snafi AE. The Pharmacological importance of Bellis perennis - Areview. InternationalJournalof Phytotherapy. 2015; 5(2): 63-69.

[26] Ghosh K, Baghel MS. A Pharmacognostical and physiochemical study of Benincasa hispida with ayurvedic review. International Journal of Research in Ayurveda \& Pharmacy. 2011; 2(6):1664-1668.

[27] Roy C, Ghosh TK, Guha D. Dose dependent activity of Benincasa hispida in colchicines-induced experimental rat model of Alzheimer's disease. International Journal of Pharmacology. 2011; 4(4):237-244.

[28] Al-Snafi AE. The Pharmacological Importance of Benincasa hispida. A review.Int Journal of Pharma Sciences and Research. 2013; 4(12): 165-170.

[29] Nazari E, Khanavi M, Amani L, Sharifzadeh M, Vazirian M, Saeedi M, et al. Beneficial effect of Brassica nigra fixed oil on the changes in memory caused by $\beta$-amyloid in an animal model . Pharmaceutical Sciences. 2020; 26(3): 261-269.

[30] Kiasalari Z, Khalili M, Roghani M, Sadeghian A. Antiepileptic and antioxidant effect of Brassica nigra on pentylenetetrazol-induced kindling in mice. Iranian Journal of Pharmaceutical Research. 2012;11(4):1209-1217.

[31] Al-Snafi AE. The pharmacological importance of Brassica nigra and Brassica rapa grown in Iraq. J of Pharm Biology. 2015; 5(4):240-253.

[32] Ramesh BN, Indi SS, Rao KSJ. Anti-amyloidogenic property of leaf aqueous extract of Caesalpinia crista. Neuroscience Letters. 2010; 475(2): 110-114.

[33] Kshirsagar SN. Nootropic activity of dried seed kernels of Caesalpinia crista Linn against scopolamine induced amnesia in mice. Int J PharmTech Res. 2011; 3(1): 104-109.

[34] Al-Snafi AE. Pharmacology and medicinal properties of Caesalpinia crista - Anoverview. International Journal of Pharmacy. 2015; 5(2): 71-83.

[35] Lin B. Polyphenols and neuroprotection against ischemia and neurodegeneration. Mini Rev Med Chem. 2011; 11(14):1222-1238.

[36] Zhu H, Wang Z, Ma C, Tian J, Fu F, Li C, Guo D, Roeder E, Liu K. Neuroprotective effects of hydroxysafflor yellow A: in vivo and in vitro studies. Planta Med. 2003; 69(5):429-433.

[37] Al-Snafi AE. The chemical constituents andpharmacological importance of Carthamus tinctorius - An overview. Journal of Pharmaceutical Biology. 2015; 5(3): 143-166.

[38] Wu CR, Lin HC, Su MH. ReversalbyaqueousextractsofCistanche tubulosafrom behavioral deficits in Alzheimer'sdisease-likeratmodel: relevance foramyloiddeposition and central neurotransmitter function. BMC Complement Altern Med. 2014;14:202-212.

[39] Guo Q, Zhou Y, Wang CJ, Huang YM, Lee YT, Su MH andLu J. An open-label, nonplacebo-controlled studyonCistanche tubulosa glycoside capsules (Memoregain ${ }^{\circledR}$ ) for treating moderate Alzheimer's Disease. Am J Alzheimers Dis Other Demen 2013;28(4):363-370.

[40] Chen Y, Li YQ, Fang JY, Li P and Li F. Establishment of the concurrent experimental model of osteoporosis combined with Alzheimer's disease in rat and the dual-effects of echinacoside and acteoside from Cistanche tubulosa. J Ethnopharmacol. 2020; 257: 112834. 
[41] Pengfei Tu, Zhihong S and Li L. Canadian Patents Database, Patent (11) CA 2457996. Medicinal preparation containing phenylethanoid glycosides extractedfrom herbaceous plant, Cistanche tubulosa (Schenk.) Wight, process of making the same, and uses of the same. Sinphar Pharmaceutical Co., 2003.

[42] Cong G. Effects of CTG on memory consolidation dysfunction of mice. Traditional Chinese Drug Research and Clinical Pharmacology. 2005; 16(3): 162-164.

[43] Oryza Oil, Fat Chemical Co. Food and cosmetic ingredients with tonics, memory improving, anti-aging, antifatigue, anti-sex dysfunction, immune boosting and fat metabolism accelerating properties of Cistanche tubulosa extract-P-25(Water-soluble Powder、Food Grade). Oryza Oil and Fat Chemical Co., Ltd. 2007.

[44] Al-Snafi AE.Bioactive metabolites and pharmacology of Cistanche tubulosa- A review.IOSR Journal of Pharmacy. $2020 ; 10(1): 37-46$.

[45] Riaz A, Khan RA, Algahtani HA. Memory boosting effect of Citruslimon,Pomegranate and their combinations. Pak J Pharm Sci.2014; 27(6): 1837-1840.

[46] Al-Snafi AE. Nutritional value and pharmacological importance of citrus species grown in Iraq. IOSR Journal of Pharmacy. 2016; 6(8): 76-108.

[47] Shahnas N, Akhila S. Phytochemical, in vitro and in silico evaluation on Clitoria ternatea for alzheimer's disease. PharmaTuto. 2014; 2(9): 135-149.

[48] Al-Snafi AE.Pharmacological importance of Clitoria ternatea - A review IOSR Journal of Pharmacy. 2016; 6(3): 68-83.

[49] Malik J, Karan M, Vasisht K. Nootropic, anxiolytic and CNS-depressant studies on different plant sources of shankhpushpi. Pharm Biol. 2011;49(12):1234-1242.

[50] Rai KS, Murthy KD, Karanth KS, Nalini K, Rao MS, Srinivasan KK. Clitoria ternatearootextract enhances acetylcholine content in rat hippocampus. Fitoterapia. 2002;73(7-8):685-689.

[51] Rai KS, Murthy KD, Rao MS, Karanth KS. Altered dendritic arborization of amygdala neurons in young adult rats orally intubated with Clitoria ternatea aqueous root extract. Phytother Res. 2005;19(7):592-598.

[52] Taranalli AD, Cheeramkuzhy TC. Influence ofClitoria ternatea extracts on memory and central cholinergic activity in rats. Pharm Biol. 2000;38(1):51-56.

[53] Rai KS, Murthy KD, Karanth KS, Rao MS. Clitoria ternatea (Linn) root extract treatment during growth spurt period enhances learning and memory in rats. Indian J Physiol Pharmacol. 2001; 45(3):305-313.

[54] Kosai R, Sirisidthi K, JiraungkoorskulK, Jiraungkoorskul W. Review on ethnomedicinal uses of memory boosting herb, butterfly pea, Clitoria ternatea.Journal of Natural Remedies. 2015; 15(2): 71-76.

[55] Dhivya PS, Sobiya M, Selvamani P, Latha S. An approach to Alzheimer's disease treatment with cholinesterase inhibitory activity from various plant species. International Journal of PharmTech Research. 2014; 6(5): 14501467.

[56] Al-Snafi AE.Medicinal importance of Colchicum candidum- A review.The Pharmaceutical and Chemical Journal. 2016; 3(2):111-117.

[57] Chattipakorn S, Pongpanparadorn A, Pratchayasakul W, Pongchaidacha A, Ingkaninan K, Chattipakorn N. Tabernaemontana divaricata extract inhibits neuronal acetylcholinesterase activity in rats. J Ethnopharm. 2007;110:61-68.

[58] Al Alkadi H, Khubeiz MJ, Jbeily R. Colchicine: A review on chemical structure and clinical usage. Infect Disord Drug Targets. 2018;18(2):105-121.

[59] Cioanca O, Hritcu L, Mihasan M, Hancianu M. Cognitive-enhancing and antioxidant activities of inhaled coriander volatile oil in amyloid $\beta(1-42)$ rat model of Alzheimer's disease. Physiol Behav. 2013;120:193-202.

[60] Mani V, Parle M, Ramasamy K, Abdul Majeed AB. Reversal of memory deficits by Coriandrum sativum leaves in mice. J Sci Food Agric. 2011; 91(1): 186-192.

[61] Mani V, Parle M. Memory- enhancing activity ofCoriandrum sativum in rats. Pharmacologyonline. 2009; 2: 827839.

[62] Cioanca O, Hritcu L, Mihasan M, Hancianu M. Cognitive-enhancing and antioxidant activities of inhaled coriander volatile oil in amyloid $\beta(1-42)$ rat model of Alzheimer's disease. Physiol Behav. 2013;120:193-202. 
[63] Zargar-Nattaj SS, Tayyebi P, Zangoori V, Moghadamnia Y, Roodgari H, Jorsaraei SG, Moghadamnia AA. The effect of Coriandrum sativum seed extract on the learning of newborn mice by electric shock: interaction with caffeine and diazepam. Psychol Res Behav Manag. 2011; 4:13-19.

[64] Al-Snafi AE. A review on chemical constituents andpharmacological activities ofCoriandrum sativum.IOSR Journal of Pharmacy. 2016; 6(7): 17-42.

[65] Khare P, Yadav G, Chaudhary S, Singh L. Investigation on protective effects ofCressa cretica extract in scopolamine- induced memory impairment. International Journal of Pharmacology and Toxicology. 2014; 2(1): 13-16.

[66] Wanjari AS, Chouragade NB. A short review of Cressa cretica. Research Journal of Pharmacology and Pharmacodynamics. 2015; 7(3): 119-123.

[67] Khare P,Yadav G, Chaudhary S,Singh L, Yadav G, Verma S. Evaluation of nootropic activity ofCressa cretica in scopolamine- induced memory impairment in mice. Int J of Pharma and Toxico. 2014; 2(2): 24-29.

[68] Priyashree S, Jha S, Pattanayak SP. A review on Cressa cretica Linn.: A halophytic plant. Pharmacogn Rev. 2010;4(8):161-166.

[69] Al-Snafi AE.The chemical constituentsandtherapeutic importance ofCressa cretica- A review . IOSR Journal of Pharmacy. 2016; 6(6): 39-46.

[70] Papandreou MA, Kanakis CD, Polissiou MG, Efthimiopoulos S, Cordopatis P, MargarityM, Lamari FN. Inhibitory activity on amyloid-beta aggregation and antioxidant properties ofCrocus sativus stigmas extract and its crocin constituents. J Agric Food Chem. 2006; 54(23): 8762-8768.

[71] Geromichalos GD, Lamari FN, Papandreou MA, Trafalis DT, Margarity M, Papageorgiou A, Sinakos Z. Saffron as a source of novel acetyl cholinesterase inhibitors: molecular docking and in vitro enzymatic studies. J Agric Food Chem. 2012; 60(24): 6131-6138.

[72] Akhondzadeh S, Shafiee Sabet M, Harirchian MH, Togha M, Cheraghmakani H, Razeghi S, Hejazi SS, Yousefi MH, Alimardani R, Jamshidi A,Rezazadeh SA, Yousefi A, Zare F, Moradi A, Vossoughi A. A 22-week, multicenter, randomized, double-blind controlled trial ofCrocus sativus in the treatment of mild-to-moderate Alzheimer's disease. Psychopharmacology (Berl). 2010; 207(4): 637-643.

[73] Abe K, Saito H. Effects of saffron extract and its constituent crocin on learning behaviour and long-term potentiation. Phytother Res. 2000; 14(3): 149-152.

[74] Dashti MH,Zeinali F,Anvari M, Hosseini SM. Saffron (Crocus sativus L.) extract prevents and improves D- galactose and NaNO2 induced memory impairment in mice. EXCLI Journal. 2012;11:328-337.

[75] ZhangY, ShoyamaY, SugiuraM, Saito H. Effects of Crocus sativus L. on the ethanol-induced impairment of passive avoidance performances in mice. Biological and Pharmaceutical Bulletin. 1994; 17(2):217-221.

[76] He WB, Zhang JL, Xue W, Hu JF, Wu DH, Chen NH. Comparison of the action of isolichenin and methanol extract of saffron on long-term potentiation in hippocampal dentate gyrus in vivo. Yao Xue Xue Bao. 2009; 44(8): 858862 .

[77] Ghadrdoost B, Vafaei AA, Rashidy-Pour A, Hajisoltani R, Bandegi AR, Motamedi F, Haghighi S, Sameni HR, Pahlvan S. Protective effects of saffron extract and its active constituent crocin against oxidative stress and spatial learning and memory deficits induced by chronic stress in rats. Eur J Pharmacol. 2011; 667(1-3): 222-229.

[78] Naghibi SM, Hosseini M, Khani F, Rahimi M, Vafaee F, Rakhshandeh H, Aghaie A. Effect of aqueous extract ofCrocus sativus L. on morphine-induced memory impairment. Adv Pharmacol Sci. 2012.

[79] Al-Snafi AE.The pharmacology of Crocus sativus- A review. IOSR Journal of Pharmacy. 2016; 6(6): 8-38.

[80] Khazdair MR, Boskabady MH, Hosseini M, Rezaee R, Tsatsakis A. The effects of Crocus sativus (saffron) and its constituents on nervous system: A review. Avicenna J Phytomed. 2015;5(5):376-91.

[81] Koppula S, Choi DK. Cuminum cyminum extract attenuates scopolamine-induced memory loss and stressinduced urinary biochemical changes in rats: a noninvasive biochemical approach. Pharm Biol. 2011; 49(7):702708.

[82] Al-Snafi AE.The pharmacological activities of Cuminum cyminum - A review. IOSR Journal of Pharmacy. 2016; 6(6): 46-65. 
[83] Tumen I, Senol FS, Orhan IE. Evaluation of possible in vitro neurobiological effects of two varieties of Cupressus sempervirens (Mediterranean cypress) through their antioxidant and enzyme inhibition actions. Türk Biyokimya Dergisi (Turk J Biochem). 2012; 37(1): 5-13.

[84] Al-Snafi AE.Medical importance of Cupressus sempervirens- A review. IOSR Journal of Pharmacy. 2016; 6(6): 6676.

[85] Senol FS, Orhan IE,Ustun O. In vitro cholinesterase inhibitory and antioxidant effect of selected coniferous tree species. Asian Pac J Trop Med.2015;8(4):269-275.

[86] Aazza S, LyoussiB, Miguel MG. Antioxidant and antiacetylcholinesterase activities of some commercial essential oils and their major compounds. Molecules. 2011; 16: 7672-7690.

[87] Khadri A, Neffati M, Smiti S, Falé P, Rosa A, Lino L, Luisa M, Serralheiro M, Eduarda M,Araújo M.Antioxidant, antiacetyl cholinesterase and antimicrobialactivities of Cymbopogon schoenanthus L. Spreng (lemon grass) from Tunisia. LWT - Food Science and Technology. 2010; 43(2): 331-336.

[88] Khadri A, Neffati M, Smiti S, Falé P, Rosa A, Lino L, Luisa M, Serralheiro M, Eduarda M, Araújo M. Antioxidant, antiacetylcholinesterase and antimicrobial activities of Cymbopogon schoenanthus L. Spreng (lemon grass) from Tunisia. LWT - Food Science and Technology. 2010; 43(2): 331-336.

[89] Al-Snafi AE. The chemical constituents and pharmacological activities of Cymbopogonschoenanthus: A review. Chemistry Research Journal. 2016; 1(5):53-61.

[90] Rabbani M, Ghannadi A, Malekian N. Evaluation oftheeffectofCyperusrotundusL. in scopolamine-induced learning deficit in mice. Adv Biomed Res. 2014;3: 217.

[91] Al-Snafi AE. A review on Cyperus rotundus A potential medicinal plant. IOSR Journal of Pharmacy. 2016; 6(7):3248.

[92] Sau S, Handral M. Evaluation of memory enhancing activity of leaf extract of Dalbergia sissoo in mice. International Journal of Pharmaceutical Sciences and Drug Research. 2015; 7(3): 263-269.

[93] Al-Snafi AE. Chemical constituents and pharmacological effects of Dalbergia sissoo - A review. IOSR Journal of Pharmacy. 2017; 7(2): 59-71.

[94] Vasudevan M, Parle M. Pharmacological evidence for the potential of Daucus carota in the management of cognitive dysfunctions. Biol Pharm Bull.2006; 29(6): 1154-1161.

[95] Mani V, Parle M , Ramasamy K, Majeed ABA. Anti-Dementia Potential of Daucus carota Seed Extract in Rats. Pharmacologyonline. 2010; 1: 552-565.

[96] Mani V, Parle M, Ramasamy K, Majeed ABA. Anti-dementia potential of Daucus carota seed extract in rats. Pharmacologyonline. 2010; 1: 552-565.

[97] Gambhir SS, Sanyal AK, Sen SP, Das PK. Studies on Daucus carota Linn. Part II. Cholinergic activity of the quaternary base isolated from water-soluble fraction of alcoholic extract of seeds. Indian J Med Res. 1966;54:1053-1056.

[98] Al-Snafi AE. Nutritional and therapeutic importance ofDaucus carota- A review. IOSR Journal of Pharmacy. 2017; 7(2): 72-88.

[99] Guilherme dos Santos J Jr, Hoffmann Martins do Monte F, Marcela Blanco M, Maria do Nascimento Bispo Lanziotti V, Damasseno Maia F,Kalyne de Almeida Leal L. Cognitive enhancement in aged rats after chronic administration of Equisetum arvense L. with demonstrated antioxidant properties in vitro. Pharmacol Biochem Behav. 2005;81(3):593-600.

[100] Al-Snafi AE. The pharmacology of Equisetum arvense- A review. IOSR Journal of Pharmacy. 2017; 7(2):31-42.

[101] JoshiH, Parle M. Cholinergic basis of memory-strengthening effect ofFoeniculum vulgare Linn.Journal of Medicinal Food. September. 2006; 9(3): 413-417.

[102] JoshiH, Parle M. Cholinergic basis of memory-strengthening effect ofFoeniculum vulgare Linn.Journal of Medicinal Food. September. 2006; 9(3): 413-417.

[103] Al-SnafiAE.The chemical constituents and pharmacological effects of Foeniculum vulgare - A review.IOSR Journal ofPharmacy. 2018; 8(5): 81-96. 
[104] Vrancheva RZ, Ivanov IG, Aneva IY, Dincheva IN, Badjakov IK, Pavlov AI. Alkaloid profiles and acetylcholinesterase inhibitory activities of Fumaria species from Bulgaria. Z Naturforsch. 2016; 71(1-2): 9-14.

[105] Chlebek J, Novák Z, Kassemová D, Šafratová M, Kostelník J, Malý L, et al . Isoquinoline alkaloids from Fumaria officinalis L. and their biological activities related to Alzheimer's disease. Chem Biodivers. 2016;13(1):91-99.

[106] Al-Snafi AE.Constituents and pharmacology of Fumaria officinalis- A review. IOSRJournal of Pharmacy. 2020; $10(1): 17-25$.

[107] Orhan I, Sener B, Choudhary MI, Khalid A. Acetylcholinesterase and butyrylcholinesterase inhibitory activity of some Turkish medicinal plants. J Ethnopharmacol. 2004; 91(1):57-60.

[108] Al-Snafi AE. Fumaria parviflora- A review. Indo Am J P Sc. 2018; 5(3): 1728-1738.

[109] Zhu Z, Li C, Wang X, Yang Z, Chen J, Hu L, Jiang H, Shen X.2,2',4'-Trihydroxychalcone from Glycyrrhiza glabra as a new specific BACE1 inhibitor efficiently ameliorates memory impairment in mice. J Neurochem. 2010; 114: 374385.

[110] Chakravarthi KK, AvadhaniR,Narayan RS . Effect of Glycyrrhiza glabra root extract on learning and memory in wistar albino rats. Int J Biol Med Res. 2012; 3(3): 2059-2064.

[111] Chakravarthi KK, Avadhani R, Narayan RS. Effects of Glycyrrhiza glabra root extract on learning and memory in wistar albino rats. Drug Invention Today. 2012; 4(7): 387-390.

[112] Chakravarthi KK, Avadhani R. Beneficial effect of aqueous root extract of Glycyrrhiza glabra on learning and memory using different behavioral models: An experimental study. J Nat Sci Biol Med. 2013;4(2):420-425.

[113] Dhingra D, Parle M, Kulkarni SK. Memory enhancing activity of Glycyrrhiza glabra in mice. J Ethnopharmacol. 2004;91(2-3):361-365.

[114] Parle M, Dhingra D, Kulkarni SK. Memory-strengthening activity of Glycyrrhiza glabra in exteroceptive and interoceptive behavioral models. J Med Food.2004; 7(4): 462-466.

[115] Desai SK, Pandey CH, Mulgaonkar SS. Memory-strengthening activity of aqueous liquorice extractand glabridin extract inbehavioral models. Int J Pharm Sci Rev Res. 2012; 16(1): 120-124.

[116] Cui YM, Ao MZ, Li W, Yu LJ. Effect of glabridin from Glycyrrhiza glabra on learning and memory in mice. Planta Med. 2008;74(4):377-380.

[117] Teltumbde AK, Wahurwagh AK, Lonare MK, Nesari TM. Effect of Yashtimadhu (Glycyrrhiza Glabra) on Intelligence and Memory Function in Male Adolescents. Sch. J App Med Sci. 2013; 1(2):90-95.

[118] Al-SnafiAE.Glycyrrhiza glabra : A phytochemical and pharmacological review. IOSR Journal of Pharmacy. 2018;8(6): 1-17.

[119] Zhao Y, Dou J, Wu T, Aisa H. Investigating the antioxidant and acetylcholinesterase inhibition activities of Gossypium herbaceam. Molecules.2013; 18(1):951-962.

[120] Liu Y,Aisa HA,Ji C,Yang N,Zhu H, Zuo P. Effects of Gossypium herbaceam extract administration on the learning and memory function in the naturally aged rats: neuronal niche improvement. J Alzheimers Dis. 2012;31(1):101111.

[121] Al-SnafiAE.Chemical constituents and pharmacological activities ofGossypium herbaceum andGossypiumhirsutum - A review. IOSR Journal ofPharmacy. 2018; 8(5): 64-80.

[122] Ibrahim NS, El. SaidAG,Mohamed YA andAli HA.In vitro inhibition of acetyl cholinestrase by Haplophyllum tuberculatum extracts. The Sixth Annual Post-graduate Studies \& Scientific Research Conference. 2015:152.

[123] Al-SnafiAE.Pharmacological importance of Haplophyllum species grown in Iraq- A review. IOSR Journal ofPharmacy. 2018;8(5): 54-62.

[124] Nazool M, Kumar S. Dual inhibition of cholinesterase enzyme by an aqueous extract of Hibiscus rosa sinensis L. International Journal of Pharma Research \& Review. 2015; 4(5):6-10.

[125] Nade VS, Kanhere SV, Kawale LA, Yadav AV. Cognitive enhancing and antioxidant activity of ethyl acetate soluble fraction of the methanol extract of Hibiscus rosa sinensis in scopolamine-induced amnesia. Indian J Pharmacol.2011; 43(2): 137-142.

[126] Nazool M, Kumar S. Dual inhibition of cholinesterase enzyme by an aqueous extract of Hibiscus rosa sinensis L. International Journal of Pharma Research \& Review. 2015; 4(5):6-10. 
[127] Al-Snafi AE.Chemical constituents, pharmacological effects and therapeutic importance of Hibiscus rosa-sinensisA review.IOSR Journal of Pharmacy. 2018; 8 (7): 101-119.

[128] Hanumanthachar J, Parle M. Nootropic activity of calyces of Hibiscus sabdariffa Linn. IJPT.2006; 5(1): 15-20.

[129] Al-Snafi AE. Pharmacological and therapeutic importance ofHibiscus sabdariffa- A review. International Journal of Pharmaceutical Research. 2018; 10(3): 451-475.

[130] Al.Hafiz LSS. Phytochemical analysis ofHypericum triquetrifoliumTurpa and assessmentof its effect on cognitive impairment caused bychronic restrain and/oracute stress. MSc thesis, Faculty of Graduate Studies Jordan University of Science and Technology. 2009.

[131] Al-Snafi AE. Chemical constituents and pharmacological effects of Hypericum triquetrifolium. Indo Am J P Sc. 2018; 5(3): 1757-1765.

[132] Orhan IE, Suntar IP, Akkol EK. In vitro neuroprotective effects of theleafandfruitextracts of Juglans regia L. (walnut) throughenzymeslinkedto Alzheimer's diseaseand antioxidant activity. Int J Food Sci Nutr. 2011;62(8):781-786.

[133] Haider S, Batool Z, Tabassum S, Perveen T, Saleem S, Naqvi F, Javed H, Haleem DJ. Effects of walnuts (Juglans regia) on learning and memory functions. Plant Foods Hum Nutr. 2011;66(4):335-340.

[134] Willis LM, Shukitt-Hale B, Cheng V, Joseph JA. Dose- dependenteffectsof walnutsonmotorandcognitive function in aged rats. Br J Nutr.2009; 101(8):1140-1144.

[135] Asadi-Shekaari M, Karimi A, Shabani M, Sheibani V, Esmaeilpour K. Maternal feedingwith walnuts(Juglans regia)improveslearning andmemoryin theiradultpups.Avicenna J Phytomed. 2013;3(4):341-346.

[136] Al-SnafiAE.Chemical constituents, nutritional, pharmacological and therapeutic importance of Juglans regia- A review. IOSR Journal of Pharmacy. 2018; 8(11): 1-21.

[137] Cioanca O, Mircea C, Trifan A, Aprotosoaie AC, L Hritcn M, Hancianu M.Improvement of amyloid- $\beta$-induced memory deficits by Juniperus communis L. volatile oil in a rat model of Alzheimer's disease. Farmacia. 2014; 62(3): 514-520.

[138] Cioanca O, Hancianu M, Mihasan M, Hritcu L. Anti-acetylcholinesterase and antioxidant activities of inhaled Juniper oil on amyloid Beta (1-42)-induced oxidative stress in the rat hippocampus. Neurochem Res. 2015;40(5):952-960.

[139] Al-Snafi AE.Medical importance of Juniperus communis - A review. Indo Am J P Sc. 2018; 5(3): $1979-1792$.

[140] Deng HB, Cui DP, Jiang JM, Feng YC, Cai NS, Li DD. Inhibiting effects of Achyranthes bidentata polysaccharide and Lycium barbarum polysaccharide on nonenzyme glycation in d-galactose induced mouse aging model.Biomed Environ Sci. 2003; 16(3): 267-275.

[141] Al-Snafi AE. Encyclopedia of chemical constituents and pharmacological effects of Iraqi medicinal plants. Rigi Publication. 2015.

[142] Chen W, Cheng X, Chen J, Yi X, Nie D, Sun X, Qin J, Tian M, Jin G, Zhang X. Lycium barbarum polysaccharides prevent memory and neurogenesis impairments in scopolamine-treated rats. Plos One. 2014; 9(2): e88076.

[143] Amagase H, Sun B, Nance DM. Immunomodulatory effects of a standardized Lycium barbarum fruit Juice in Chinese older healthy human subjects. Journal of Medicinal Food. 2009; 12(5):1159-1165.

[144] Maurmanna N, de Fariasa CB, Schwartsmannc G, Roeslera R, Delgado-Hernándezg R, Pardo-Andreub GL. Mangifera indica L extract (Vimang) improves the aversive memory in spinocerebellar ataxia type 2 transgenic mice. Journal of Pharmacy \& Pharmacognosy Research. 2014; 2(3): 63-72.

[145] Wattanathorn J, Muchimapura S, Thukham-Mee W, Ingkaninan K, Wittaya-Areekul S. Mangifera indica fruit extract improves memory impairment, cholinergic dysfunction, and oxidative stress damage in animal model of mild cognitive impairment. Oxid Med Cell Longev. 2014.

[146] Kumar S, Maheshwari KK, Singh V. Effects of Mangifera indica fruit extract on cognitive deficits in mice. J Environ Biol. 2009; 30(4):563-566.

[147] Preissler T, Martins MR, Pardo-Andreu GL, Henriques JA, Quevedo J, Delgado R, Roesler R. Mangifera indica extract (Vimang) impairs aversive memory without affecting open field behaviour or habituation in rats. Phytother Res. 2009; 23(6):859-862. 
[148] Al-Snafi AE, Ibraheemi ZAM, Talab TA. A review on components and pharmacology of Mangifera indica. International Journal of Pharmaceutical Research. 2021; 13(2): 3043- 3066.

[149] Ionita R, Postu PA, Mihasan M, Gorgan DL, Hancianu M, Cioanca O, Hritcu L. Ameliorative effects of Matricaria chamomilla L. hydroalcoholic extract on scopolamine- induced memory impairment in rats: A behavioral and molecular study. Phytomedicine. 2018; 47: 113-120.

[150] Bora KS, Sharma A. Evaluation of antioxidant and cerebroprotective effect of Medicago sativa Linn against ischemia and reperfusion insult. Hindawi Publishing Corporation Evidence- Based Complementary and Alternative Medicine. 2011.

[151] Liu XG, Lv MC, Huang MY, Sun YQ, Gao PY, Li DQ. A network pharmacology study on the triterpene saponins from Medicago sativa L for the treatment of neurodegenerative diseases. J Food Biochem. 2019; 43(8): e12955.

[152] Al-Snafi AE. Khadem HS, Al-Saedy HA, Alqahtani AM, El-Saber Batiha G. Jafari-Sales Abolfazl.A review on Medicago sativa: A potential medicinal plant. International Journal of Biological and Pharmaceutical Sciences Archive. 2021; 1(2):22-33.

[153] Bazazzadegan N, Dehghan Shasaltaneh M, Saliminejad K, Kamali K, Banan M, Khorram Khorshid HR. The effects of Melilotus officinalis extract on expression of Daxx, Nfkb and Vegf genes in the streptozotocin-induced rat model of sporadic Alzheimer's disease. Avicenna J Med Biotechnol. 2017;9(3):133-137.

[154] Al-Snafi AE. Chemical constituents and pharmacological effects of Melilotus Officinalis- A review. IOSR Journal of Pharmacy. 2020; 10(1):26-36.

[155] Ozarowski M, Mikolajczak PL, Piasecka A, et al. Influence of the Melissa officinalis leaf extract on long-term memory in scopolamine animal model with assessment of mechanism of action. Evid Based Complement Alternat Med. 2016;9729818.

[156] Ahmadi R, Selot FS, Pishghadam S. Effects of Melissa officinalis on ethanol state-dependent learning in nicotinetreated mice. MOJ Anatomy \& Physiology. 2016; 2(1): 30.

[157] Dastmalchi K, Ollilainen V, Lackman P, et al. Acetylcholinesterase inhibitory guided fractionation of Melissa officinalis L. Bioorg Med Chem. 2009; 17(2): 867-871.

[158] Kennedy DO, Wake G, Savelev S, et al. Modulation of mood and cognitive performance following acute administration of single doses of Melissa officinalis (Lemon balm) with human CNS nicotinic and muscarinic receptor-binding properties. Neuropsychopharmacology. 2003; 28(10): 1871-1881.

[159] Kennedy DO, Scholey AB, Tildesley NT, Perry EK, Wesnes KA. Modulation of mood and cognitive performance following acute administration of Melissa officinalis (lemon balm). Pharmacol Biochem Behav. 2002; 72(4): 953964.

[160] Akhondzadeh S, Noroozian M, Mohammadi M, et al. Melissa officinalis extract in the treatment of patients with mild to moderate Alzheimer's disease: a double blind, randomised, placebo controlled trial. J Neurol Neurosurg Psychiatry 2003; 74: 863-866.

[161] Metwally FM, Rashad H and Mahmoud AA. Morus alba L. Diminishes visceral adiposity, insulin resistance, behavioral alterations via regulation of gene expression of leptin, resistin and adiponectin in rats fed a highcholesterol diet. Physiol Behav 2019; 201:1-11.

[162] Niidome T, Takahashi K, Goto Y, Goh S, Tanaka N, Kamei K, Ichida M, Hara S, Akaike A, Kihara T and Sugimoto H. Mulberry leaf extract prevents amyloid beta-peptide fibril formation and neurotoxicity. Neuroreport 2007; 18(8): 813-816.

[163] Turgut NH, Mert DG, Kara H, Egilmez HR, Arslanbas E, Tepe B, Gungor H, Yilmaz N, Tuncel NB. Effect of black mulberry (Morus nigra) extract treatment on cognitive impairment and oxidative stress status of D-galactoseinduced aging mice. Pharm Biol. 2016; 54(6): 1052-1064.

[164] Whitehouse PJ, Martino AM, Antuono PG, Lowenstein PR, Coyle JT, Price DL, Kellar KJ. Nicotinic acetylcholine binding in Alzheimer's disease. Brain Res. 1986; 371:146-151.

[165] Ksir C, Benson DM. Enhanced behavioral response to nicotine in an animal model of Alzheimer's disease. Psychopharmacology. 1983; 81:272-273.

[166] Wilson AL, Langley LK, Monley J, Bauer T, Rottunda S, McFalls E, et al. Nicotine patches in Alzheimer's disease: pilot study on learning, memory, and safety. Pharmacol Biochem Behav. 1995; 51:509-514. 
[167] Perveen T, Abdullah A, Haider S, Sonia B, Munawar AS, et al. Long-term administration of Nigella sativa effects nociceotion and improves learning and memory in rats. Pak J Biochem Mol Biol. 2018; 41: 141-143.

[168] Vafaee F, Hosseini M, Hassanzadeh Z, Edalatmanesh MA, Sadeghnia HR, Seghatoleslam M, Mousavi SM, Amani A, Shafei MN. The effects of Nigella sativa hydroalcoholic extract on memory and brain tissues oxidative damage after repeated seizures in rats. Iran J Pharm Res. 2015;14(2):547- 557.

[169] Norouzi F, Hosseini M, Abareshi A, Beheshti F, Khazaei M, Shafei MN, Soukhtanloo M, Gholamnezhad Z and Anaeigoudari A. Memory enhancing effect of Nigella sativa hydroalcoholic extract on lipopolysaccharide-induced memory impairment in rats. Drug Chem Toxicol. 2019; 42(3):270-279.

[170] Anaeigoudari A, Norouzi F, Abareshi A, Beheshti F, Aaghaei A, Shafei MN, Gholamnezhad Z, Hosseini M. Protective effects of Nigella sativa on synaptic plasticity impairment induced by lipopolysaccharide. Vet Res Forum. 2018;9(1):27-33.

[171] Fanoudi S, Alavi MS, Hosseini M, Sadeghnia HR. Nigella sativa and thymoquinone attenuate oxidative stress and cognitive impairment following cerebral hypoperfusion in rats. Metab Brain Dis. 2019; 34(4):1001-1010.

[172] Beheshti F, Hosseini M, Shafei MN, Soukhtanloo M, Ghasemi S, Vafaee F, Zarepoor L. The effects of Nigella sativa extract on hypothyroidism-associated learning and memory impairment during neonatal and juvenile growth in rats. Nutr Neurosci. 2017; 20(1): 49-59.

[173] Hosseini M, Mohammadpour T, Karami R, Rajaei Z, Sadeghnia HR, et al. Effects of the hydro-alcoholic extract of Nigella sativa on scopolamine-induced spatial memory impairment in rats and its possible mechanism. Chinese Journal of Integrative Medicine. 2015; 21: 438-444.

[174] Topcagic A, Cavar Zeljkovic S, Karalija E, Galijasevic S, Sofic E. Evaluation of phenolic profile, enzyme inhibitory and antimicrobial activities of Nigella sativa L. seed extracts. Bosn J Basic Med Sci. 2017;17(4):286-294.

[175] Bin Sayeed MS, Asaduzzaman M, Morshed H, Hossain MM, Kadir MF. The effect of Nigella sativa Linn. seed on memory, attention and cognition in healthy human volunteers. J Ethnopharmacol. 2013; 148: 780-786.

[176] Bin Sayeed MS, Shams T, Fahim Hossain S, Rahman MR, Mostofa A. Nigella sativa L. seeds modulate mood, anxiety and cognition in healthy adolescent males. J Ethnopharmacol. 2014; 152: 156-162.

[177] Singh V, Krishan P, Shri R. Improvement of memory and neurological deficit with Ocimum basilicum L. extract after ischemia reperfusion induced cerebral injury in mice. Metab Brain Dis. 2018; 33(4): 1111-1120.

[178] Sarahroodi S, Esmaeili S, Mikaili P, Hemmati Z, Saberi Y. The effects of green Ocimum basilicum hydroalcoholic extract on retention and retrieval of memory in mice. Anc Sci Life. 2012; 31(4): 185-189.

[179] Singh V, Kahol A, Singh IP, Saraf I, Shri R. Evaluation of antiamnesic effect of extracts of selected Ocimum species using in vitro and in vivo models. J Ethnopharmacol. 2016; 193:490-499.

[180] Al-Snafi AE. Chemical constituents and pharmacological effects of Ocimum basilicum- A review. International Journal of Pharmaceutical Research. 2021; 13(2): 2997-3013.

[181] Aruna K, Rajeswari PDR, Sankar SR. The effect of Oxalis corniculata extract against the behavioral changes induced by 1- methyl- 4-phenyl-1,2,3,6-tetrahydro pyridine (MPTP) in mice. Journal of Applied Pharmaceutical Science. 2017; 7(03): 148-153. 